\title{
Do people manage climate risk through long-distance relationships?
}

\author{
Anne C. Pisor ${ }^{1,2 *} \&$ James Holland Jones ${ }^{3}$
}

\section{[ACCEPTED MANUSCRIPT: AMERICAN JOURNAL OF HUMAN BIOLOGY]}

\author{
${ }^{1}$ Department of Anthropology, Washington State University, Pullman, WA 99164-4910 \\ ${ }^{2}$ Department of Human Behavior, Ecology, \& Culture, Max Planck Institute for Evolutionary \\ Anthropology \\ ${ }^{3}$ Department of Earth System Science, Stanford University \\ *Corresponding author: anne.pisor@wsu.edu
}

Objectives. Long-distance social relationships have been a feature of human evolutionary history; evidence from the paleoanthropological, archaeological, and ethnographic records suggest that one function of these relationships is to manage the risk of resource shortfalls due to climate variability. We should expect long-distance relationships to be especially important when shortfalls are chronic or temporally positively autocorrelated, as these are more likely to exhaust local adaptations for managing risk. Further, individuals who experience shortfalls not as rare shocks, but as patterned events, should be more likely to pay the costs of maintaining longdistance relationships. We test these hypotheses in the context of two communities of Bolivian horticulturalists, where climate variability - especially precipitation variability - is relevant to production and access to long-distance connections is improving. Methods. Data on individuals' migration histories, social relationships, and other relevant variables were collected in 2017 $(n=119)$. Precipitation data were obtained from the US National Center for Atmospheric Research, allowing us to estimate participants' exposure to drought and excess precipitation. Results. Exposure duration, proximity in time, and frequency did not predict having a greater number of long-distance relationships. Males, extraverted individuals, and those who had traveled more did have more long-distance relationships, however. Conclusion. Another function of long-distance relationships is to access resources that can never be obtained locally; ethnographic data suggest this is their primary function in rural Bolivia. We conclude by refining our predictions about the conditions under which long-distance relationships are likely to help individuals manage the risks posed by climate variability.

Keywords: climate change, adaptation, cooperation, social networks, human behavior 


\section{INTRODUCTION}

Climate change is one of the most pressing issues facing humans in the early $21^{\text {st }}$ century. However, humans are no strangers to climate change: it has influenced hominin evolution, including the evolution of hominin social systems, since our last common ancestor with chimpanzees and bonobos (Pisor \& Jones, this issue). Climate variability, such as fluctuation in precipitation, affects human livelihoods by increasing the risk of resource shortfalls. Data from contemporary and past human communities reveal a number of common behavioral adaptations individuals use to manage the shortfalls associated with climate variability, including building connections with social partners who live at a distance, outside local communities (Pisor \& Surbeck, 2019). Using a typology we developed to describe climate variability (Pisor \& Jones, n.d.), we hypothesize that individuals will be more likely to invest in long-distance relationships when intervals of low or high levels of precipitation are long-lasting, clustered together in time, and patterned (as opposed to rare). We evaluate these hypotheses in the context of two communities of Bolivian horticulturalists in which individuals differ in their past exposures to drought, floods, and landslides. Our exploration offers insight, not only to anthropologists, but to the climate community (including policymakers, international organizations, and climateoriented social scientists) with respect to the adaptations humans already use to manage climate change and how these adaptations are relevant to coping with climate change going forward.

\subsection{Why do humans show flexible interest in long-distance social relationships?}

Humans are flexibly interested in building social relationships that span distance: we sometimes exhibit aggression and sometimes exhibit tolerance toward individuals from other places (Pisor \& Surbeck, 2019). Though often conflated with inter-group relationships, by which researchers usually implicitly mean "between-ethnic-group relationships," long-distance relationships are distinct in that they cross community boundaries - where communities are groups of individuals who live in spatial proximity (Rodseth et al., 1991) - but may or may not cross ethnic boundaries (Brewer \& Campbell, 1976; Hruschka et al., 2014; Purzycki et al., 2016). Indeed, the selection pressures that may have favored long-distance relationships in humans are likely distinct from those that favored between-ethnic-group relationships (Pisor \& Ross, n.d.; see also Moya \& Boyd, 2015). Our flexible interest in long-distance relationships is documented by literatures studying "expanding circles" of moral concern (Fessler et al., 2015; Purzycki \& Lang, 2019; Singer, 1981) and the role of "superordinate identity" in promoting cooperation (Buchan et al., 2009; Pisor \& Gurven, 2015): in both cases, if individuals value people farther away as potential social partners, their behavior towards them changes. Research studying behavior towards strangers also often inadvertently captures long-distance relationships because individuals who are geographically nearby are more likely to be known to a focal individual than individuals further away (Pisor \& Ross, n.d.).Long-distance trade in the archaeological (Braun \& Plog, 1982; Fitzhugh et al., 2011; Halstead \& O'Shea, 1989) and paleoanthropological records (Bouzouggar et al., 2007; Brooks et al., 2018; Foley \& Gamble, 2009) and the structure of hunter-gatherer social networks (Bird et al., 2019; Cashdan, 1985; Chapais, 2008; Hill et al., 2014; Wiessner, 1982) support the importance of long-distance relationships for accessing resources - both in the past and present, as well as across the evolutionary history of our genus, Homo. 
While bonobos and gorillas are also flexibly tolerant toward rarely-encountered individuals or strangers (Bermejo, 2004; Fruth \& Hohmann, 2018; Lucchesi et al., 2020; Tan et al., 2017), the degree to which humans rely on relationships with rarely-encountered individuals is unique among the great apes (Pisor \& Surbeck, 2019). Our flexible interest in long-distance relationships is likely an adaptation to our foraging ecology and our high energy throughput, suggesting that far-flung social connections have likely been a feature of human social networks since the origins of Homo (Pisor \& Surbeck, 2019). Long-distance relationships function to manage the risk of local resource shortfalls - especially those that can strike an entire community, debilitating everyday cooperative partners - and to provide access to patchy resources that are not present in many communities, such as markets or high-quality toolmaking materials (Pisor \& Surbeck, 2019). While these relationships are especially important in egalitarian societies (Minc \& Smith, 1989), they remain important even in post-industrial societies, particularly when hazards - things that cause downsides in income or production - destroy government systems of support (Fafchamps, 1992). All else equal, we should expect individuals to be interested in long-distance relationships when the expected benefits of these relationships (e.g., in terms of resource access) outweigh the costs of maintaining them (e.g., travel time or the risk of attack in transit; Minnis, 1985).

Because of the relevance of long-distance relationships throughout human evolutionary history, we would expect that if an individual receives cues that long-distance relationships may provide net benefits, their evolved psychology will respond with increased interest in forming these relationships (Pisor \& Gurven, 2018; Pisor \& Surbeck, 2019). Evidence from contemporary peoples suggest that we are indeed sensitive to these payoffs, as individuals are more likely to build social ties "bridging" communities when there are benefits to doing so (Granovetter, 1973; Nannestad et al., 2008; Woolcock \& Narayan, 2000) and negative past experiences with strangers can reduce individuals' willingness to trust (Yamagishi, 2011) or be generous toward strangers (Pisor \& Gurven, 2018). Cultural institutions can further enhance the net benefits of long-distance relationships (Pisor \& Surbeck, 2019); for example, seasonal meetings among mobile foraging peoples can reduce the cost of visiting long-distance social partners (Kelly, 2007), while "godparent" relationships can increase the intensity of cooperation between long-distance partners (Mintz \& Wolf, 1950).

\subsection{How might climate variability impact the formation of long-distance relationships?}

Environments are risky: in other words, they produce variable outcomes, with both uncertain gains (upsides) and uncertain losses (downsides), for the organisms in them (Jones et al., this issue). Climate, including precipitation and temperature, is part of the environment in which organisms live, and climate variability thus entails risk. Adaptations work to manage the risks posed by the environment (Jones et al., this issue). For example, plants have adaptations that may respond to small increases in precipitation by increasing fruit production, but respond to decreases in precipitation by decreasing fruit production, thus creating a shortfall in a resource on which consumers depend (Dunham et al., 2018) - not only human consumers, but, in a second-order effect on our livelihoods, the animals we eat (Dunham et al., 2018). Downsides are bad for fitness: if shortfalls are bad enough and an individual runs out of resources, an entire lineage can go extinct (Gillespie, 1977; Price \& Jones, 2020). In short, climate variability, including 
the increased variability that is a function of climate change (Field et al., 2014; Pendergrass et al., 2017), puts humans and other organisms at risk of resource shortfalls.

Long-distance relationships are part of a suite of behavioral adaptations that humans use to maintain access to resources given the risk of shortfalls. These adaptations include mobility, including short-term and long-term mobility; savings, including household-level food storage and, for market-integrating or market-integrated peoples, monetary savings; diversification, including increased diet breadth or diversification in crops planted or in income sources; force, including raiding, warfare, and stealing; pooling, including reciprocity between social partners and redistribution of pooled resources; and exchange (Bollig, 2006; Colson, 1979; Halstead \& O'Shea, 1982, 1989; Spielmann, 1986; Winterhalder et al., 1999). These adaptations have different functions with respect to risk, including reducing it (e.g., diet diversification), retaining it - absorbing it at the household level (e.g., savings), and transferring it - shifting risk from one individual to another (e.g., pooling; Aktipis et al., 2011; Wiessner, 1977). Importantly, increased investment in one adaptation can increase the cost of another. For example, investment in physical storage can limit physical mobility (Cashdan, 1985); using force can limit future possibilities for exchange (Minnis, 1985).

Long-distance relationships are often central to several of these adaptations, including mobility, pooling, and exchange. Pooling among cooperative partners, for example, can take place either within or across community boundaries (O'Shea, 1981); while short-term or long-term mobility does not technically require long-distance social connections, migrants often travel to where they know someone (Palloni et al., 2001), especially if knowing someone is necessary for accessing resources at their destination (Wiessner, 1982; Wilson, 1998). Whether long-distance relationships provide net benefits, however, depends on risk being idiosyncratic across individuals (Cashdan, 1985; Fafchamps, 1992). If two social partners experience a resource shortfall at the same time, they will be unable to transfer risk (Aktipis et al., 2011) - that is, engage in pooling or exchange. Because resource shortfalls vary in spatial and temporal scales, some risks can be managed within households or through sharing with neighbors (Jaeggi et al., 2016), while those that strike larger areas or that are longer-lasting often cannot (Pisor \& Surbeck, 2019). For example, if environmental downsides are clustered in time, an individual may exhaust their savings as they have to draw repeatedly on their stored resources without making additional contributions; if downsides are clustered in space, same-community members are likely to also be in dire straits, leading to the breakdown of within-community resource pooling (Colson, 1979).

How "long" must long-distance relationships be to reach someone with a different experience of risk? The distance between individuals $A$ and $B$ will be a function of the spatial scale of the shortfall, the local ecology, and how A and B make a living. The larger the spatial scale of relevant hazards, the further away $B$ must be from $A$ for their experience of risk to be idiosyncratic; for example, while a nearby B might face idiosyncratic risk from a tornado, a B must be further away to face idiosyncratic risk from a hurricane. Ethnographic examples suggest that individuals know how far away is far enough and maintain relationships across these distances accordingly (Minc \& Smith, 1989; Waddell, 1975; Wiessner, 1982). When resources are diverse across short distances, as is common in places with variable topography (Halstead \& O'Shea, 1982), or are 
available at different times (Harpending \& Davis, 1977), as is common when communities specialize in different resources (Barth, 1969), a B from a nearby community may still have resources available with which to help $A$. Indeed, when $A$ and $B$ have different means of making a living - for example, if one is a pastoralist and the other a forager (Headland \& Reid, 1989), or if they have different professions - their risks are less likely to be correlated even across smaller distances.

We can formulate a priori hypotheses about which adaptations individuals will use to manage which kinds of shortfalls. For example, under what circumstances do humans rely on longdistance relationships instead of raiding (Pisor \& Surbeck, 2019)? Elsewhere, we propose a typology of three contrasts that permit such a priori predictions: we suggest that we can better predict which adaptations humans will use to manage the effects of climate variability if we decompose this variability by the degree to which it is acute or chronic, more or less positively autocorrelated in time or space, and patterned or rare (Pisor \& Jones, n.d.). All else equal, we hypothesize that individuals will be more likely to form long-distance relationships when the downsides of environmental risk (and related resource shortfalls) are chronic, positively autocorrelated in space or time, and patterned. When shortfalls are chronic - that is, long-lasting - or positively autocorrelated - that is, one predicts another, whether in time or space - local adaptations for risk management are more likely to be depleted (Minnis, 1985; Pisor \& Jones, n.d.). Further, because of the costs of maintaining long-distance relationships, we should not expect individuals to invest these relationships unless they anticipate needing them in the future. Accordingly, individuals should be unlikely to invest in long-distance relationships unless downsides are patterned - that is, recurrent. Rare shocks, or anticipation of downsides that have never occurred locally, are unlikely to favor investment in long-distance relationships (Minnis, 1985; Pisor \& Jones, n.d.). See Figure 1 for a summary of these concepts.

$\mathbf{A}$

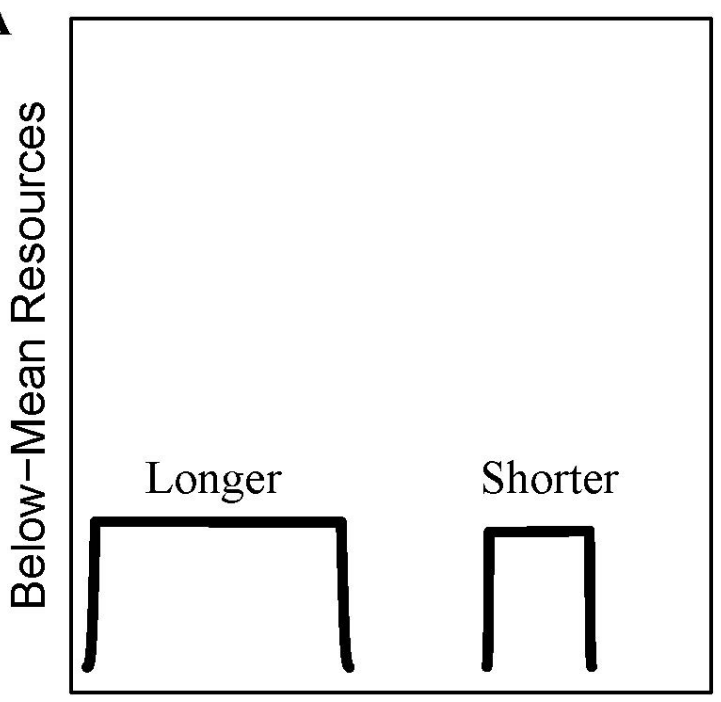

Time

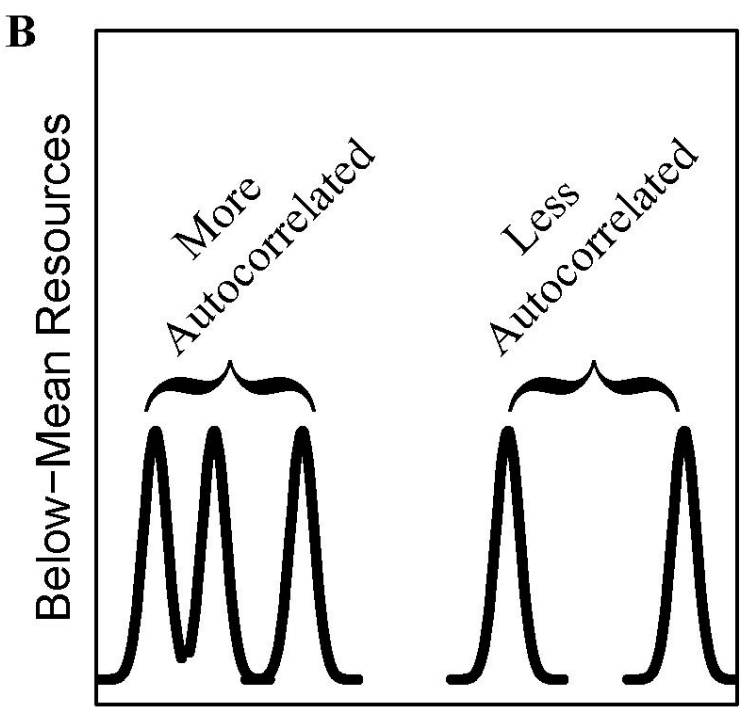

Time 


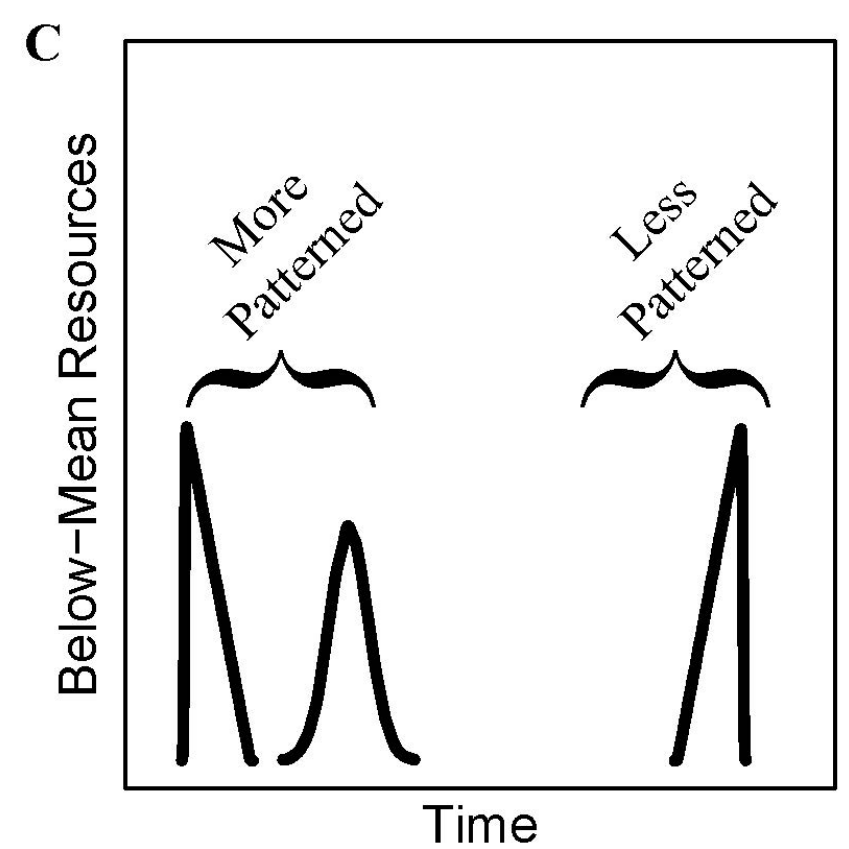

Figure 1. For illustration, we compare hypothetical resource shortfalls that differ in their (a) duration (that is, how chronic they are), (b) positive temporal autocorrelation (how clustered they are together in time), and (c) patterning (whether they are experienced as rare shocks or not). Note that the y-axis represents how far an individual falls below their mean access to resources; in other words, the higher the shortfall goes on the $y$-axis, the worse the shortfall.

\subsection{Are long-distance relationships used to manage climate variability in Bolivia?}

We evaluate these a priori hypotheses in the context of rural lowland Bolivia, where AP collaborates with two communities of horticulturalists (slash and burn farmers). Long-distance relationships have been a constant feature of Bolivian life, predating the arrival of Europeans by at least a millennium. For Andean highland populations, social connections spanning elevation often between highland source populations and colonists living in the cloud forests or lowlands - facilitated the movement of goods, people, and religious practices (Klein, 2011). In the lowlands, contact and trade covered large distances, connecting both hunter-gatherers and horticulturalists living in large settlements (Barlow et al., 2012). These connections likewise moved goods, people, cultural practices, and languages (Clement et al., 2015; Lathrap, 1973; Nordenskiöld, 1915; Reeve, 1993).

Like many countries in the Global South, Bolivia has fallen victim to the effects of contemporary climate change, including changes in both the averages and the variability of temperature and precipitation (Seiler et al., 2017). Among the most common natural disasters Bolivia experiences, three of the four - floods, droughts, and landslides - are all related to precipitation, either low or excess (World Bank Group, 2020). Increased variability in precipitation is a fundamental feature of most global climate projections (Pendergrass et al., 2017), with a generally increased likelihood of extreme precipitation events in the future (e.g., Prein et al., 2017; Ragno et al., 2018).

The communities with whom AP collaborates have been feeling the effects of precipitation variability. Given the hilly local terrain and tropical climate, farmers rely on horticultural 
production, finding plowing and irrigation unworkable. While floods, landslides, and drought have been common features of their lives, farmers report that it never used to be like it is today. When AP visited in 2012, participants reported being in the throes of a two-year local drought, leading to decreased cash crop and subsistence production, especially for drought-intolerant crops like cacao and rice. When she returned in 2014, excess precipitation had triggered floods and landslides throughout the lowlands, leaving community members with most of their crops destroyed and without power, cell service, or serviceable roads - and thus without access to market foods, banks, or hospitals - for over a month. When she returned in 2017, the communities had just experienced yet another drought the previous year.

Despite these recent shared experiences of precipitation variability, many individuals in these communities have disparate earlier experiences of low and excess precipitation. Both communities are characterized by migration: while some individuals were born elsewhere and migrated to the community, others engage in short-term mobility to participate in migrant labor, usually as a complement to household horticultural production; complete mandatory military service; or have extended visits with friends or family. Given that participants differ in their exposure to low and excess precipitation, we can expect that their interest in long-distance relationships may likewise vary. Note that this assumes that environmental cues from earlier in life affect current preferences and behavior, even following migration (Young et al., 2020). Existing data indicating that preferences and behavior often persist in migrants following a move (e.g., Berry, 1997) suggests that this is a reasonable baseline assumption.

If long-distance relationships are indeed an adaptation that individuals use to manage the risk of shortfalls when shortfalls tend to be chronic, positively autocorrelated, and/or patterned, we would expect individuals who have experienced these conditions to invest more in long-distance relationships, all else equal. (As low levels of precipitation entail drought, while high levels can trigger both floods and landslides, we use drought as synonymous for low levels here.) Given the relevance of drought and excess precipitation to Bolivian horticulturalists, we make the following predictions with respect to their long-distance relationships:

(H1) Individuals who have more experience with chronic downsides will be more likely to report having long-distance social relationships than those who have less chronic exposure to downsides.

(P1) Participants who have, on average, experienced longer intervals of (a) drought or (b) excess precipitation will report a greater number of friendships with people who live outside their community.

(H2) Individuals who have experienced more positive temporal autocorrelation between downsides will be more likely to report having long-distance social relationships than those who have experienced less positive temporal autocorrelation.

(P2) Participants who have experienced shorter intervals of reprieve between intervals of drought and excess precipitation will report a greater number of friendships with people who live outside their community. 
(H3) Individuals who have experienced downsides repeatedly will be more likely to report having long-distance social relationships than those who have experienced downsides as rare shocks.

(P3) Participants who have experienced a greater number of (a) unusually dry months or (b) unusually wet months, scaled by the total number of months for which we have data on their precipitation exposure, will report a greater number of friendships with people who live outside their community.

Because droughts and excess precipitation affect individuals in Bolivia differently - for example, excess precipitation can limit contact by destroying roads or communications infrastructure, while drought usually has no equivalent effects - we separately assess their effects on longdistance relationship formation in (P1) and (P3). Further, to evaluate whether chronic, positively autocorrelated, and/or patterned exposure to drought or excess precipitation specifically increase investment in long-distance relationships, or whether they increase investment in all social relationships, we evaluate each of the above predictions with respect to reciprocity-based within-community relationships as well.

\section{METHODS}

\subsection{Collaborating communities}

The two communities with whom AP collaborates live in a river valley in the La Paz Department of Bolivia. Both communities practice horticulture, including both subsistence and cash cropping. Ninety-four percent of households own or rent fields and incomes are commonly supplemented by wage labor, usually in others' fields ( $43 \%$ of households). The first community is a multicultural (intercultural) community while the second has a plurality of Mosetén residents; we refer to the first as Intercultural and the second as Mosetén. We focus here on the role of long-distance social relationships in these communities; other details about each community can be found in Supporting Information 1.

When both communities were founded, neither had access to a road. Opportunities for longdistance relationships were present but fewer than those available today and, due to the demands of childcare, mostly restricted to males. Males combined river, mule, and foot travel with buses connecting the market town to La Paz and other, smaller regional centers to trade, attain market goods, and engage in wage labor. After roads arrived - to the Intercultural community in 1975 and the Mosetén community in 2000 - participation in migrant labor (Pareja, 1999), commercial sales, and educational opportunities increased, but disproportionately for males relative to females. Further, mandatory military service, a year of which is required for all males, was increasingly enforced. Today, males report having visited or lived in a greater number of other departments or countries than females (1.56 vs 1.15) and report a greater number of long-distance relationships (2.13 vs 1.22).

Mobility and migration, contact with middlemen, and military service have increased access to long-distance relationships for both communities, but so too has access to cell service and the 
purchase of personal vehicles. Both communities have had access to electricity since 2007, to cellular service since 2009, and to data service since 2016, although cell and data service do not reach all households in the Mosetén community. Data service and smartphones have been especially key to maintaining long-distance relationships, as data is significantly cheaper per unit time than phone calls. AP can attest to the importance of data service and smartphones: she has worked in Bolivia since 2010, and while before 2016 she needed to call her Bolivian friends to keep in touch, they now regularly contact her using WhatsApp and Facebook. In both communities, approximately 3 in 10 households own a vehicle. Two in 10 households primarily use their vehicles for horticultural work and one in 10 primarily as shared taxis, transporting passengers to their garden plots or the market town. Many vehicle owners also use their vehicles to occasionally visit friends and family living at a distance.

Long-distance relationships are created and maintained through a variety of means, including travel, marriage, and fictive kinship. Friendship (amistad) is forged through repeated or longterm interactions with middlemen, co-workers, fellow soldiers, classmates, and participants in regional retreats or political events. Consanguineal kinship can also provide the basis for longdistance relationships. Reciprocity-based relationships with kin are often less expensive to maintain than reciprocity-based relationship with friends (Hruschka, 2010); however, given high rural fertility - as of 2012, total completed fertility (living children only) was 5 for the Intercultural community and 6.5 for the Mosetén community - individuals report that they are selective when it comes to maintaining close relationships with siblings and cousins, focusing on those who reciprocate. Affinal kin are also common connections - unsurprising, as humans often strategically use marriage to forge between-community relationships and gain resource access (Chapais, 2008; Pisor \& Surbeck, 2019). For example, some members of the Mosetén community accuse non-Mosetén males of marrying Mosetén females to gain access to tribal lands for horticulture or logging. Catholics in both communities also strategically use fictive kinship (specifically, godparent relationships) to solidify long-distance relationships with those they believe are best able to help them or their children.

\subsection{Data collection}

In March-June 2017, AP interviewed 119 participants about their migration histories, longdistance relationships, same-community relationships, household possessions, self-described extraversion, and demographics. Given variable literacy across participants but familiarity with signing documents, consent forms were read aloud and participants provided written (that is, signed) consent. All field protocols were approved by the Max Planck Institute for Evolutionary Anthropology Department of Human Behavior, Ecology, and Culture, and declared exempt from additional IRB oversight. More details on data collection and on the limitations of the predictors described appear in the Supporting Information.

\subsubsection{Migration histories}

Participants were asked to name the departments (the equivalent of provinces) in which they had lived or to which they had traveled during their lives. Participants reported each interval they spent in another department, including how long they were there and at what age. There are limitations to this reporting method. Because AP did not ask for dates of travel - only age and 
length of stay - we cannot be sure which months of the year participants were in a particular department; as precipitation varies seasonally, this limits our ability to infer precipitation exposure. We therefore estimate a participant's precipitation exposure based on where they lived for a year or longer. If participants did not report living in another department during a particular year of their life, we assumed that they were in the La Paz Department - the location of the two collaborating communities. A few participants $(n=9)$ had lived outside of Bolivia, either because they were born there $(n=2)$, lived there as children $(n=1)$, or completed migrant labor there ( $n=7$; one returned to his birthplace for work). Three named the departments in which they had lived in these other countries; for the other six participants, AP assigned participants their probable department of residence using other data from their interviews $(n=2)$ or data indicating the most common department in which Bolivians live in that country ( $n=4$; Pereira Morató, 2011). Two participants reported living in another location for 1.5 and 2.5 years respectively; we rounded these values up to the nearest whole year.

\subsubsection{Long-distance relationships}

AP asked participants to count their number of friends "who live elsewhere, whom they see only once in a while"; to indicate whether they and these friends "help each other" or "do favors for each other" (that is, engage in reciprocity); and to describe the nature of the help or favors. Participants named between zero and eight people as friends living elsewhere. These friends lived at distances ranging from five kilometers to thousands of kilometers away. However, as only 11 participants had more than three connections - including just three participants with five connections and one participant each with six, seven, or eight connections - we bin those participants into the category of three or more so that the thresholds estimated during the model-fitting process (Section 2.4.1) are not based on single or very few observations. The 11 participants with more than three long-distance connections were predominantly males $(n=9)$, had visited more places, and were more extraverted than other participants (see Section 2.2.4 for more details on these variables).

Commonly reported help and favors provided by long-distance friends included monetary loans, encomiendas (packages shipped by bus that contain foods and market items not locally available), and lodging. For a participant to have access to non-local resources in times of shortfall, presumably they must have a reciprocity-based relationship with their long-distance friends. However, $49 \%$ of participant-friend dyads did not help one another; participants sometimes clarified that they and their friend only reciprocated friendship (sólo amistad). As a robustness check, we assess whether there is a relationship between exposure to drought or excess precipitation and the number of long-distance friends who engage in reciprocity with the participant (Section 2.4.3). Because only 21 participants named two or more reciprocity-based long-distance relationships, we bin those who named two or more relationships with those who named two.

\subsubsection{Same-community relationships}

It is possible that the relationship between drought or excess precipitation exposure and a participant's number of social connections is not specific to long-distance connections, but instead extends to all social connections (Section 1.3). Accordingly, we assess the relationship 
between drought or excess precipitation exposure and the presence of a same-community connection (Section 2.4.2). AP asked participants whether there were any other households in the community that are "doing favors for you and your household" or "help you and your household." She asked only about the first household with which participants reported such a relationship; as such, we parameterize same-community relationships as either present or absent. Participants were also asked to name the favors or help the other household provided (the most common responses were loaning tools, loaning money, and exchanging labor), to name the favors or help they provided in turn, and to report their relationship to that household (e.g., neighbors, kin, friends). Given that it may be less costly for participants to maintain relationships with consanguineal kin (Section 2.1), as a robustness check we code same-community relationships as "present" only if the household named was not related to the participant by blood (Section 2.4.2). Note however that only 16 participants reported non-consanguineal kin same-community relationships, compared to 71 participants who reported consanguineal samecommunity relationships.

\subsubsection{Control variables}

Independently of their experience of precipitation, some participants will simply have had more opportunities to forge long-distance relationships than others. We identified six variables that capture these differential opportunities. First, participants who are older have spent a smaller proportion of their lives with access to roads and cell or data service than younger individuals, and without roads or communications infrastructure, long-distance relationship formation was more costly. On the other hand, age could have the opposite effect on long-distance relationship formation, as older individuals have had more time to form these relationships than younger individuals. Second, since the road to the Mosetén community is twenty-five years newer than the road to the Intercultural community, this may have contributed to community-level differences in opportunities for mobility. There are, of course, a number of other differences between these communities that could have unobserved effects. Third, males in these communities have higher mobility than females and thus greater opportunity to forge longdistance relationships. Fourth, participants with access to smartphones and to personal vehicles will have an easier time maintaining long-distance relationships than those who do not. Fifth, individuals who are more outgoing (that is, more extraverted) may initiate more social relationships in general (Ashton \& Lee, 2007; Nettle, 2006), including with long-distance partners. Finally, individuals who have traveled more have had more opportunity to form long-distance relationships through direct contact - even if they only visited a location temporarily.

We include each of these variables as controls (or, in the case of community, random effects) in our models. Participants were asked to self-report their year of birth; as asking participants to identify their sex or gender is considered a strange question in this context, a research assistant recorded the participant's sex based on their outward presentation. In these communities, participants provide AP the birth year on their identification card; note however that for older individuals, the year on their identification card is more likely to be an estimate they reported to government officials. Participants self-reported household-owned market possessions, including smartphones and vehicles. They also indicated their self-perception of their extraversion using two modified questions from the Newcastle Personality Assessor (Nettle, 2009). For these two 
questions, AP used emergent Likert scales based on open-ended responses from participants; accordingly, one item has three possible responses ("always," "sometimes," and "never") and one item four possible responses ("always," "sometimes," "rarely," and "never"). We assigned numeric values to each response ("never" $=1$ ) and summed responses across the two questions. From participants' migration histories (Section 2.2.1), we count the number of other countries and the number of departments outside the La Paz Department in which participants have spent a month or more cumulatively across their lifetimes; note that this includes both departments in which participants spent a year or more (per Section 2.2.1) and departments in which they completed multiple shorter (e.g., several day) visits.

Another variable that could affect not just differential opportunity, but differential interest in long-distance relationships is the use of an alternate adaptation, namely diversification (Section 1.2). Although almost all sources of income in this community are either directly or indirectly dependent on cash cropping - for example, individuals cannot pay wages to laborers, purchase groceries, or pay for taxis without cash - it is possible that households with more diversification of their sources of income may have less need for long-distance relationships. Participants reported between zero and four sources of household income over the previous month. We conduct exploratory robustness checks, analyses we did not pre-register, to assess whether number of income sources affects number of long-distance connections. These results are reported in Section 3.6.

\subsection{Precipitation data}

Precipitation accumulation data were downloaded from the NCAR Computational and Information Systems Laboratory (Standardardized Precipitation Index (SPI) for Global Land Surface (1949-2012), 2013). Data were available for January 1, 1949 through December 31, 2012 and are reported at the granularity of one latitude by one longitude cells globally. As is common practice in meteorological science, daily precipitation accumulation data were averaged by threemonth windows and normalized to a standard normal distribution, such that values above zero indicate more precipitation than average and values below zero less precipitation than average for a given window (e.g., January-February-March) and a given one latitude by one longitude cell (e.g., -16 latitude, -68 longitude) across all years, 1949-2012 (Orlowsky \& Seneviratne, 2013). These values are called the Standardized Precipitation Index (SPI) and are reported for the month at the midpoint of the three-month interval (e.g., February for January-February-March). By common practice, when the SPI for a given month is at or below - 1 (that is, -1 standard deviation) the month is considered "dry," and when the SPI is at or above one, the month is considered "wet" (Svoboda et al., 2012). Indeed, when the SPI reaches -1, common practice is to call this a drought for the grid cell in question; the length of the drought is determined by the length in months during which the SPI was below zero (McKee et al., 1993). The same logic holds for excess precipitation: if the SPI goes above zero and reaches one before returning to zero, that interval is labeled excess precipitation; if the SPI does not reach one, it is not considered an interval of excess precipitation.

We estimated participants' precipitation exposures using a combination of their migration histories and the SPI data. With shapefiles delimiting the boundaries of each department in Bolivia and in neighboring countries (Hijmans, n.d.), we matched the grid of SPI values to 
departments. As AP did not ask about locations visited within each department, we averaged the SPI by month for each department (e.g., averaged the SPI values for all grid cells within the La Paz Department for January 2012). For each month of their life, participants were then assigned a departmental SPI value based on the department in which they were living. Recall that participants were asked only how long they had spent in each department and the ages during which they were there (Section 2.2.1), such that we can only draw inferences about stays in a department lasting a year or longer. As participants also provided only their birth year rather than birth date, for simplicity we treat all participants as born on January 1 of their birth year; if they reported spending a year in a particular department (e.g., Santa Cruz Department) at a given age (e.g., 21, when they were born in 1985), we assign them the department SPI values for that entire year (e.g., the average SPI in Santa Cruz for January-December 2006).

We calculated predictors (P1-3) using the following procedures:

(P1) We estimated a participant's exposure to chronic drought and chronic excess precipitation by taking (a) the average length of all drought intervals they experienced and (b) the average length of all excess precipitation intervals they experienced. Note that if a participant moved from one department to another during a drought interval, if the second department had an SPI below 0 when the participant arrived, we treat the drought interval as if it continued, because the participant's exposure to below-average rainfall continued even though they moved departments; this is consistent with our reasoning that exposures can affect preferences and behaviors even after migration (Section 1.3). However, if the second department had an SPI at or above 0 when the participant arrived, we closed the drought interval. We likewise continued excess precipitation intervals following a move if the second department had an SPI above 0 when the participant arrived.

(P2) To estimate a participant's experience of positive temporal autocorrelation in downsides (both drought and excess precipitation), we calculated the length of the intervals during which a participant was not experiencing either a drought or excess precipitation. We then took the average length of these intervals, producing a single measure of average latency between events of drought and excess precipitation.

(P3) We estimated a participant's patterned exposure to drought and patterned exposure to excess precipitation by summing the months during which the participant experienced (a) an SPI of -1 or lower (a dry month), and (b) an SPI of 1 or higher (a wet month). As we are interested in whether variation in precipitation is experienced as patterned or as a rare shock, we divided this sum by the total months of the participant's life for which we have precipitation data (19492012) to get the frequency of wet months and dry months during their lifetime. We chose to use dry and wet months to estimate (P3) rather than drought intervals or excess precipitation intervals (as we did for (P1)) because $(\mathrm{H} 3)$ is specific to the frequency of experience of downsides. For example, two individuals may have each experienced 20 months of -1 SPI, but perhaps Individual A has experienced four intervals of drought, each with five months at -1 , but Individual B has experienced two intervals of drought, each with 10 months at -1 . By the McKee et al. (1993) definition, Individual A has experienced more droughts than Individual B, but both have equal experience with bad months - when production is likely to be impacted by low precipitation - such that for both $A$ and $B$, low precipitation is not a rare shock. As such, we 
evaluate H3 using total months of experience of -1 or lower SPI (or +1 or higher SPI, for excess precipitation) rather than total intervals of drought or excess precipitation.

\subsection{Statistical methods}

All models reported here were implemented in $R$ version 4.0.2 ( $R$ Core Team, 2020) with package brms (Bürkner, 2017), a package that runs Bayesian models in Stan (Stan Development Team, 2020). We centered all continuous variables such that zero indicates the minimum observed value in the sample. The data set, metadata, and code can be found at http://doi.org/10.5281/zenodo.4065638.

\subsubsection{Analyzing the predicted relationships}

We constructed five separate models to investigate the relationship between a participant's number of long-distance relationships and their chronic, positively autocorrelated, and patterned exposure to droughts and excess precipitation. There are two reasons we constructed five separate models instead of one. First, (P1-3) all capture the nature of a participant's exposure to variability in precipitation and are thus not independent. For example, because the average length of intervals between downsides (P2) is not independent of the average duration of drought or of excess precipitation events (P1) - as the former goes up, the latter two will go down - these predictors should not be included in the same model. Second, we model drought and excess precipitation separately because the two affect participants differently and thus may differentially impact the formation of long-distance relationships (Section 1.3). Further, dry or wet months, or intervals of drought or excess precipitation, are mutually exclusive: a participant cannot experience a drought and excess precipitation at the same time. Given that drought and excess precipitation are not independent and may have different effects on long-distance relationship formation, we model drought and excess precipitation separately in (P1) and (P3); as (P2) refers to intervals free of both drought and excess precipitation, only one model is needed.

The predicted relationships were analyzed with sequential models with continuous parameterization and a logit link function. After binning higher values for number of longdistance relationships (see Section 2.2.2), participants could have only 0-3 long-distance connections. With so few potential values for the outcome variable, normality assumptions are violated. Further, the data are not generated by a Poisson process: individuals move between different levels across time (e.g., an individual must have two long-distance friends before they can have three), and the thresholds between these different levels are not necessarily equidistant (e.g., it may be much more difficult for an individual with zero long-distance friends to form a relationship with one than for an individual with one long-distance friend to form a relationship with a second). Accordingly, we treat long-distance relationships as ordinal and use a sequential model. For further details on these models, see Supporting Information 3.1. As an exploratory robustness check, we assess whether a Poisson modeling approach, without binning the number of long-distance relationships, generates qualitatively similar results; these results are reported in Section 3.7.

Included in these five sequential models are a random effect for community of residence and fixed effects for all control variables (Section 2.2.4). We use a random effect for community such 
that we can pool our estimates at the community level; this is more appropriate than pooling data across both communities when estimating parameters, as these two communities differ in important ways (Section 2.1). We use weakly informative priors for all variables (Supporting Information 3.2).

\subsubsection{Analyzing an alternative outcome}

We assessed whether the effects of chronic, positively autocorrelated, and/or patterned exposure to drought and excess precipitation were specific to long-distance relationship formation, or apply to the formation of any relationships, by investigating whether these exposures also predict the presence of same-community relationships. Because the presence of a same-community relationship is a binary variable, we conducted these analyses using a logistic regression in brms. Like we did for the sequential models described above, we again included community of residence as a random effect, included control variables as fixed effects, and used weakly informative priors.

\subsubsection{Robustness checks of the outcomes}

As discussed in Section 2.2.2, it is possible that the effects we predicted in (P1-3) are specific to long-distance relationships based on reciprocity, not just recognition of friendship. Further, when considering whether same-community relationships are also predicted by chronic, positively autocorrelated, and/or patterned exposure to drought or excess precipitation, it is possible that any effect is specific to same-community relationships forged with non-consanguineal kin, not to relationships with both kin and non-kin individuals (Section 2.2.3). We modeled the effects of (P1-3) on each of these two outcomes as robustness checks, using a sequential model (described in Section 2.4.1) to model reciprocity-based, long-distance relationships, and a logistic model (described in 2.4.2) to model same-community relationships with non-consanguineal kin. All other model parameters and priors remained the same.

\subsubsection{Robustness checks of the predictors}

Exploratory data analysis suggested that outliers in the predictors of interest (P1-3) may influence model fit. We assessed the influence of these individual points on model fit for each of the five models described in Section 2.4.1. Two influential outliers were excluded when fitting the drought model for (P1); however, outliers were not influential in the fits of the other four models and thus were not excluded from the fitting process. (See Supporting Information 3.4 for further details.)

\subsubsection{Robustness checks of control variables}

AP forgot to ask one participant about their extraversion. We imputed values for this participant using predictive mean matching implemented with the mi ce package (Van Buuren \& GroothuisOudshoorn, 2011) and used these imputed data to fit all models described above. As a robustness check, we excluded this participant and refit each model. Their exclusion did affect model estimates in some cases, as we report in Section 3.5.

\subsubsection{A note on results reporting}


As all models reported here use a logit link function and are Bayesian, we report results using odds ratios (ORs) and $90 \%$ credible intervals ( $\mathrm{Cls}$ ). We explain how ORs and Cls work in Supporting Information 3.6. Briefly, we use $90 \% \mathrm{Cls}$ because (1) Cls are typically wider than confidence intervals, as Bayesian models better account for uncertainty than frequentist models, and (2) the 95\% criterion can be unstable for $\mathrm{Cls}$, requiring extensive sampling during the model-fitting process (Kruschke, 2014). As the OR estimate for intercepts - including the thresholds for transitioning from zero to one long-distance relationship, one to two, etc. - do not have a straightforward interpretation, we do not report these here.

\section{RESULTS}

Participants had experienced variable lengths of intervals of drought (mean length in months $=6.39, \mathrm{SD}=0.46$, range $=4.46-7.25$ ), of excess precipitation (mean length $=5.80, \mathrm{SD}=0.82$, range $=4.42-7.85$ ), and free of drought or excess precipitation (mean length $=6.75, \mathrm{SD}=0.93$, range $=4.72-11.89$ ). For comparison, note that from 1949-2012 in the La Paz Department, the mean length of intervals of drought was 7.09 and of excess precipitation was 6.56; deviation from these values among participants reflects differences in their ages and experiences of migration. Participants also had a large range of experience with dry months (26-80 months; $7.4-15.6 \%$ of their lifetimes for which we had data) and wet months (21-88; 6-18.8\%), indicating variability in exposure to patterned precipitation (dry month $\mathrm{SD}=13.87$, wet month $\mathrm{SD}=16.58$ ). Participants' modal number of long-distance relationships was one, and $73 \%$ of participants had a samecommunity reciprocity-based relationship with someone. Further descriptive statistics appear in Tables S1a-d.

\section{1 (H1) Chronic exposure to downsides will be associated with a greater number of long- distance social relationships}

Participants who had experienced longer average intervals of drought or longer average intervals of excess precipitation were no more likely to have long-distance social relationships than participants who had experienced shorter average intervals of drought or excess precipitation (Figure 2; Figure S1). This was true whether we considered all long-distance connections or just those that are based on reciprocity (drought: all relationships $\mathrm{OR}=0.69 \quad(\mathrm{Cl}=0.35-1.37)$, reciprocity-based $\mathrm{OR}=1.72(\mathrm{Cl}=0.81-3.75)$; excess precipitation: all relationships $\mathrm{OR}=1.39$ $(\mathrm{Cl}=0.90-2.17)$, reciprocity-based $\mathrm{OR}=0.88 \quad(\mathrm{Cl}=0.53-1.46))$. Likewise, the effect of chronic exposure to downsides did not impact other social relationships measured: the presence of a same-community relationship based on reciprocity - even limiting this to a same-community relationship with non-consanguineal kin - was not associated with either longer average intervals of drought or of excess precipitation (Figures S2 \& S3; drought: all relationships OR=0.59 ( $\mathrm{Cl}=0.20$ 1.67), non-consanguineal $\mathrm{kin} O \mathrm{OR}=0.71(\mathrm{Cl}=0.17-2.75)$; excess precipitation: all relationships $\mathrm{OR}=1.02(\mathrm{Cl}=0.52-1.95)$, non-consanguineal kin $\mathrm{OR}=0.84(\mathrm{Cl}=0.29-2.35))$. 

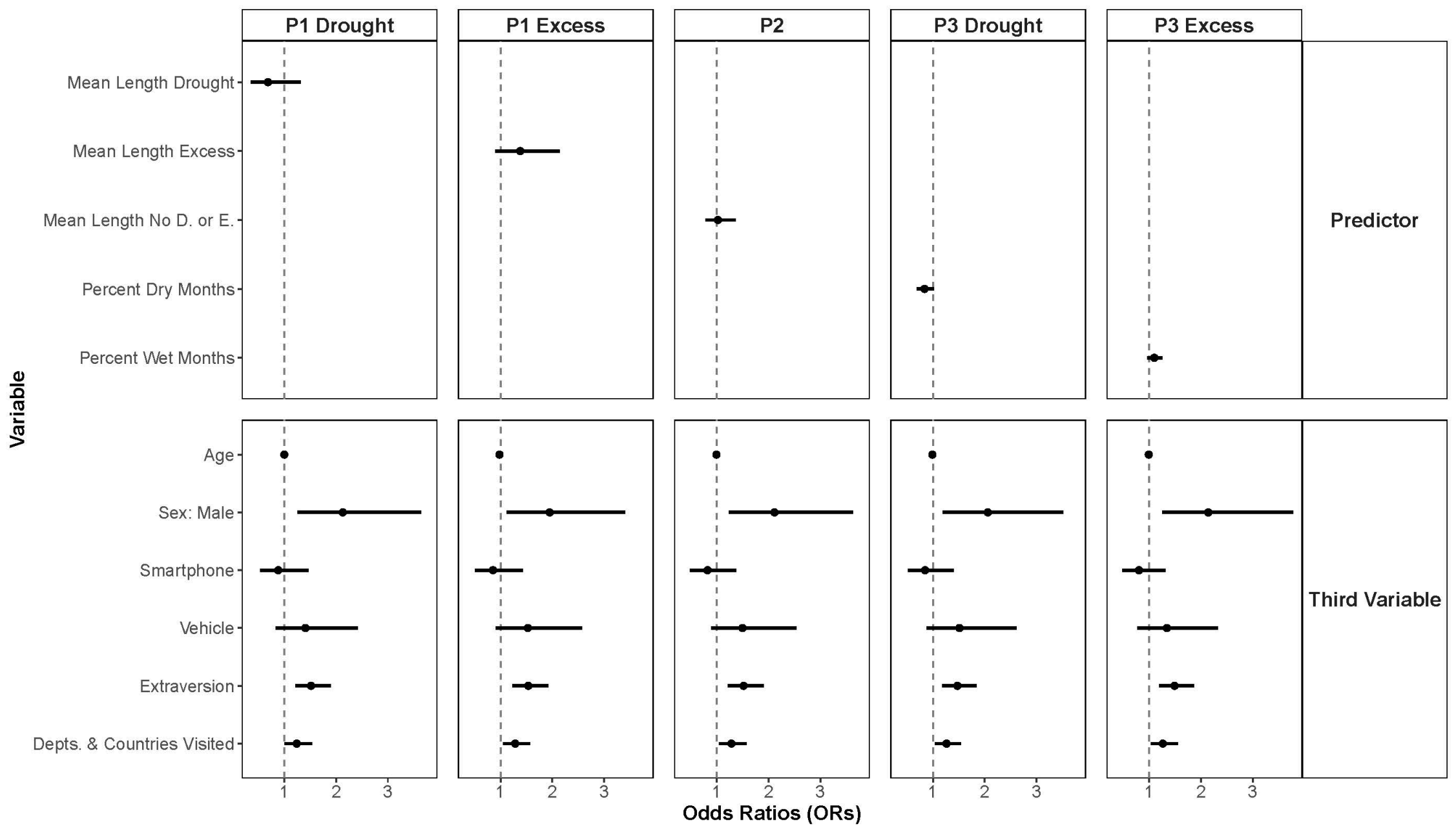

Figure 2. Parameter estimates and $90 \%$ credible intervals for the five main models, treating long-distance relationships as the outcome. 
3.2 (H2) Experience of positive temporal autocorrelation between intervals of downsides will be associated with a greater number of long-distance social relationships

Participants who had experienced shorter average intervals between downsides - that is, shorter intervals free of drought or excess precipitation - were no more likely to have long-distance social relationships than participants who had experienced longer average intervals (Figure 2; Figure S1); this was true for both all long-distance relationships and the subset of long-distance relationships that are based on reciprocity (all relationships $\mathrm{OR}=1.02(\mathrm{Cl}=0.77-1.37)$, reciprocitybased $\mathrm{OR}=1.12(\mathrm{Cl}=0.82-1.58))$. Same-community relationships based on reciprocity, including the subset of non-consanguineal same-community relationships, were also not associated with shorter intervals between downsides (Figures S2 \& S3; all relationships $O R=1.43(\mathrm{Cl}=0.88-2.46)$, non-consanguineal kin $\mathrm{OR}=1.22(\mathrm{Cl}=0.68-2.09))$.

3.3 (H3) Experience of downsides that are more patterned (that is, less like rare shocks) will be associated with a greater number of long-distance relationships

Participants who had experienced a higher frequency of dry months or wet months were no more likely to have long-distance social relationships than participants who had experienced a lower frequency of dry or wet months (Figure 2; Figure S1). Again, this was true both when we considered all long-distance relationships or only the subset that involve reciprocity (drought: all relationships $\mathrm{OR}=0.84(\mathrm{Cl}=0.68-1.02)$, reciprocity-based $\mathrm{OR}=1.01 \quad(\mathrm{Cl}=0.80-1.29)$; excess precipitation: all relationships $\mathrm{OR}=1.10(\mathrm{Cl}=0.96-1.25)$, reciprocity-based $\mathrm{OR}=0.90 \quad(\mathrm{Cl}=0.76$ 1.06)). The effect was likewise not present for same-community reciprocity-based relationships, including for only those same-community relationships with non-consanguineal kin (Figures S3 \& S4; drought: all relationships $\mathrm{OR}=0.83(\mathrm{Cl}=0.61-1.12)$, non-consanguineal kin $\mathrm{OR}=0.84(\mathrm{Cl}=0.54$ 1.29); excess precipitation: all relationships $\mathrm{OR}=1.02(\mathrm{Cl}=0.83-1.25)$, non-consanguineal kin $\mathrm{OR}=0.82(\mathrm{Cl}=0.60-1.09))$.

\subsection{The effects of control variables}

Consistently across the five main models (Figure 2), males, participants who are more extraverted, and participants who have visited a greater number of departments or countries for a month or more were more likely to have an additional long-distance social relationship. Taking just the first model, the (P1) drought model, as an example, male participants were more than twice as likely to have an additional long-distance connection ( $\mathrm{OR}=2.14, \mathrm{Cl}=1.25-3.66)$; for each increase of one integer on the extraversion scale, participants were one and a half times as likely to have an additional long-distance connection ( $\mathrm{OR}=1.46, \mathrm{Cl}=1.17-1.84)$; and for each additional department or country visited for a month or more, participants were 1.24 times as likely to have an additional long-distance connection ( $\mathrm{OR}=1.24, \mathrm{Cl}=1.01-1.52)$. The relationships between being male and between departments or countries visited and long-distance connections held for the subset of connections that were reciprocity-based, though the Cls for being extraverted included an OR of 1 (Figure S1). None of these variables predicted whether a participant had a samecommunity relationship (Figure S2), although extraversion was a consistent predictor of having a same-community, non-consanguineal relationship (Figure S3). Owning a vehicle was also a robust predictor of having a non-consanguineal, same-community relationship: participants who owned 
one were approximately five times more likely to have a non-consanguineal, same-community relationship across all models (Figure S3). However, recall that few participants ( $n=16$, or $13 \%$ of the total sample) reported a non-consanguineal, same-community relationship, such that this effect is driven by a few data points.

A random effect for community was included in each model. One can obtain estimates for random effects, examining whether the $\mathrm{Cl}$ for the intercept for a community includes an OR of 1 . Across the five main models, all estimates for random effects included an OR of 1, suggesting that community of residence did not predict having an additional long-distance relationship.

\subsection{Robustness checks of control variables}

Data were imputed for the extraversion scale for one participant. To assess the robustness of our model fits to their inclusion, we re-ran the five main models with this participant excluded. Their exclusion did not affect model fits, with the exception that the Cls for departments or countries visited in the (P1) drought model and for being male in the (P1) excess precipitation model shifted to include an OR of 1; the participant's exclusion did not affect estimates for extraversion, the variable for which we imputed their data.

\subsection{Exploratory analysis: Robustness check of diversity of income sources}

Across all five main models, number of household income sources did not predict having another long-distance relationship. Inclusion of this predictor blunted the effect of number of departments or countries visited, such that the Cls in three of the five models included an OR of 1 , but the effects of sex and extraversion remained consistent across all models.

\subsection{Exploratory analysis: Robustness check of sequential vs Poisson modeling approaches}

Because sequential models are appropriate for analyzing the data in question (Section 2.4.1), we did not pre-register analyses using a Poisson modeling approach. Further, we did not pre-register analyses in which higher-level observations for number of long-distance relationships were not binned, as so few participants reported having more than three long-distance connections and model estimates based on so few observations are inappropriate when estimating thresholds in sequential models (Section 2.2.2). However, we find that sequential and Poisson approaches produce qualitatively similar results for the five main models, even when long-distance connections are not binned: there were consistent effects only for participant sex, extraversion, and number of departments or countries visited.

\section{DISCUSSION}

Climate variability has been a consistent feature of human evolution (Pisor \& Jones, this issue), entailing a risk of resource shortfalls that humans manage using a suite of behavioral adaptations. Long-distance social relationships are often key to several of these adaptations, including mobility, pooling, and exchange; however, long-distance relationships can be costly to build and maintain. Given their cost, we hypothesized that individuals will be more likely to have longdistance relationships when the downsides of climate variability are chronic, temporally positively autocorrelated, and patterned (as opposed to rare) - that is, when individuals are more 
likely to draw on their long-distance connections to manage resource shortfalls. In two communities of Bolivian horticulturalists, we found that individual differences in experience of average duration of drought and excess precipitation, of average time between intervals of drought and excess precipitation, and of frequency of unusually dry or wet months did not predict having a greater number of long-distance relationships - or, for that matter, having a same-community, reciprocity-based relationship. We did find, however, that participants who were male, more extraverted, and had visited a greater number of locations more were likely to have an additional long-distance connection (see Section 4.1 for further discussion).

These results are consistent with ethnographic data from these two communities. Another common function of long-distance relationships is to gain access to patchy resources only available in some communities (Pisor \& Surbeck, 2019), which appears to be the primary function of long-distance relationships in rural Bolivia. Community residents identify their long-distance connections as individuals who know where to find work in migrant labor, send packages of specialty foods and market items, provide short- or long-term lodging, and help navigate government bureaucracy (Section 2.2.2). In contrast, when asked who could loan money during a hypothetical flood, $66 \%$ of participants named someone in the same community (Supporting Information 4); when AP asked why not someone from elsewhere, participants pointed out that during the 2014 flood, they could not reach their long-distance connections even if they wanted to, either by phone or by car. Instead, even though community residents feel that climate variability is worse now than it was in the past, adaptations that do not require long-distance relationships, especially savings and within-community pooling (Section 1.2), are still sufficient to manage downsides. For example, when floods or landslides strike, households often slaughter their pigs and chickens and switch to consuming their cash crops for subsistence; during the 2014 flood, this sustained most households for over a month. Government aid fulfilled the remaining demand for food, and those who could not absorb the cost of their lost cash crops took out bank loans. Though droughts do not cut off road or data access, community members manage droughts with different adaptations as well: for example, members of the Intercultural community loan each other bags of rice, repaying in kind the following year. In an exploratory analysis, we did not find any evidence that diversification of income sources reduced a participant's number of long-distance relationships (Sections 2.2.4, 3.6). However, given the tight linkage between horticultural production and most income sources in these communities, this is unsurprising: a downside in production cannot easily be managed by other activities dependent on production. In short, even though access to long-distance connections has improved over the last few decades, individuals continue to utilize community-based adaptations for managing the downsides of climate variability; long-distance relationships instead provide access to patchy resources available only in other locales, as they have in Bolivia since long before European contact (Section 1.3).

If not those experienced by these two communities of Bolivian horticulturalists, under what conditions might we expect that exposure to chronic, positively temporally autocorrelated, and patterned downsides favors the formation of and investment in long-distance relationships? We highlight two considerations. First, it may be that most horticultural groups fall into such a narrow range of the variation in downsides that long-distance relationships are not a common means of risk management. However, several known horticulturalist groups use short-term mobility to 
manage risk, dispersing to visit friends and family during droughts, high-intensity frosts, and other potential sources of community-wide famine (Table 2; Spielmann, 1986). Indeed, the Tsimane', a group with a long history of intermarriage with the Mosetén, still regularly use visitation (sobaqui) to call upon the resources of consanguineal kin or affines during times of shortfall; the Mosetén greatly reduced their practice of visitation as they became more involved in cash cropping. In short, though long-distance relationships are often less long in highproductivity environments relative to low-productivity environments (Section 1.2), they are still present. Further, for both horticulturalist and non-horticulturalist groups, mobility is often used as a last resort, when downsides are of such high impact or long duration that all locally based adaptations are exhausted (Forbes, 1989; McLeman, 2018; Spielmann, 1986; Waddell, 1975) consistent with the hypotheses in this paper (Section 1.2). Even during the flood of 2014, the two collaborating communities did not exhaust their local options, and given landslides that washed out roads, the cost of mobility was high. In sum, horticulturalists do appear to experience downsides chronic enough to favor risk management via long-distance connections. However, existing data suggest that horticulturalists are primarily utilizing long-distance relationships for either access to non-local resources (as are the Mosetén and Interculturales) or for mobility in response to downsides, rather than for exchange or pooling (Spielmann, 1986). Accordingly, if mobility is reduced by participation in the market economy, or if local adaptations are sufficient to manage most climate variability, the utility of long-distance relationships for risk management is likewise reduced.

Along this vein, given the sometimes high cost of forming and maintaining long-distance relationships (Section 1.2; Fitzhugh et al., 2011; Minnis, 1985), one should consider the availability and comparative cost of alternative adaptations when making predictions about the relevance of long-distance relationships for managing downsides. As we and others have outlined, humans have a number of behavioral adaptations for managing risk, including mobility, diversification, savings, force, pooling, and exchange; some of these, especially mobility, pooling, and exchange, can involve long-distance relationships (Section 1.2; Agrawal, 2010; Colson, 1979; Halstead \& O'Shea, 1982, 1989; Pisor \& Jones, n.d.-b; Spielmann, 1986; Thornton \& Manasfi, 2011). When the cost of one of these adaptations goes down or up, the relative net benefits of the others change. For example, the availability of bank-based savings and loans or government programs can crowd out between-community pooling systems: when local adaptations are near exhausted, as they were during the 2014 floods in Bolivia, government assistance can substitute for long-distance relationships (Pan, 2009). Further, to recap our discussion in Section 2.1, while vehicles and data service reduced the cost of long-distance relationships for the collaborating communities, making mobility, between-community pooling, and exchange more affordable, cash cropping increased the cost of mobility - with the exception of migrant labor, as this often complements rather than replaces household horticultural production. Ethnographic data about the costs and benefits of alternative adaptations can provide suggestive evidence for whether long-distance relationships will be part of individuals' risk management portfolios.

Even though residents of these two Bolivian communities are not using long-distance social relationships to respond to climate variability, the climate community (including policymakers, international organizations, and climate-oriented social scientists) should be attuned to the relevance of long-distance relationships for managing the downsides of contemporary climate 
change. An abundance of archaeological evidence suggests that individuals used long-distance relationships to respond to climate change in the past (Braun \& Plog, 1982; Douglass \& Rasolondrainy, this issue; Freeman et al., 2017; Halstead \& O'Shea, 1982; Minc \& Smith, 1989; Minnis, 1985) and both ethnographic and quantitative data demonstrate that they continue to do so today (Bird et al., 2019; Cashdan, 1985; Wiessner, 1982). Researchers wish to better understand locally emergent adaptations for managing climate change so that they can promote these responses around the globe (Jones et al., this issue); overlooking the potential role of longdistance relationships - even if they ultimately end up being of little relevance in a particular context, as was the case in the two Bolivian communities - will provide only a partial picture of the suite of climate-change adaptations humans are using.

\subsection{The effects of sex, visitation, and extraversion}

We found that males, individuals who had visited a greater number of departments or countries, and those who were more extraverted were more likely to have an additional long-distance social relationship. Ethnographic and interview data indicate that males have always had higher mobility in these communities, a pattern reinforced by migrant labor participation and mandatory military service (Section 2.1) and consistent with data from other populations (Miner et al., 2014; Vashro \& Cashdan, 2015). Because of higher mobility, males have simply had more opportunities to form long-distance relationships than have females. Beyond the effect of sex, individuals in our sample varied in their histories of migration and mobility; though associated variation in precipitation exposure did not predict the number of long-distance friends, unsurprisingly more exposure to candidate long-distance friends did. Finally, more extraverted individuals are more likely to form social relationships in general (Ashton \& Lee, 2007; Nettle, 2006), including - as our findings seem to suggest - long-distance relationships.

\subsection{Limitations}

Though we discussed how both positive temporal and positive spatial autocorrelation of downsides - that is, clustering of downsides in time or space - could deplete local adaptations, increasing the net benefits of long-distance relationships, we did not investigate the role of spatial autocorrelation in this paper. In a different paper, we take a theoretical approach to spatial autocorrelation and its role in the formation of long-distance social relationships (Jones \& Pisor, n.d.). For example, the 2014 flood affected so many in the Bolivian lowlands, long-distance connections elsewhere in the lowlands would have been in no position to help: effective risk management would have required individuals to have long-distance connections in the Andes or some other location unlikely to be affected by widespread flooding. To this point, because AP asked about friends "who live elsewhere" rather than specifying a particular distance, the longdistance friends named by participants lived from five to thousands of kilometers away. Accordingly, the friends in the present sample would vary in their ability to help. In this paper, we only analyzed how many connections a participant reported outside of their community; in Jones and Pisor (n.d.), we ask how far away connections must live to help an individual manage resource shortfalls.

Along this vein - consideration of which long-distance connections might be better positioned to help during times of shortfall - it would also be reasonable to consider whether a diversified risk 
management portfolio included not only long-distance connections in various locations, but also in various professions. For example, if a drought strikes the entire La Paz Department, connections working in an industry other than agriculture might be best able to help an individual from a horticultural community, regardless of whether they live in the capital city or just down the road. We do not have information on the occupations of participants' long-distance connections, but this strategy for diversifying one's portfolio should be studied in future work.

Though participants in this sample differ in their exposures to drought and excess precipitation, their experiences are not hugely variable. Precipitation does vary in the Bolivian lowlands, both within and across years (Godoy et al., 2008), but unless participants are mobile or are different ages, we should expect few to no differences between them in their exposures. Mobility and age are responsible for some variability in exposure in this sample - for example, approximately 10 percent of all months experienced by participants were unusually dry or unusually wet, with SDs of 1.31 and 1.92 respectively. However, because we are interested in cumulative experience with chronic downsides $(\mathrm{H} 1)$ and with temporal positive correlation between downsides $(\mathrm{H} 2)$, we summarized participants' exposures by calculating the mean length of all drought intervals, excess precipitation intervals, and intervals between downsides they had experienced (respectively, mean drought length $=6.39, \mathrm{SD}=0.46$; mean excess precipitation length $=5.80$, $\mathrm{SD}=0.82$; mean interim interval=6.75, $\mathrm{SD}=0.93$ ); summarizing constrains observed variability across participants. Unless members of a population are particularly mobile, researchers may be hard-pressed to find inter-individual differences in exposure large enough to account for differences in number of long-distance relationships. Future work on the subject should perhaps consider whether differential investment in long-distance relationships across, rather than within, populations can be explained by differential exposure to downsides.

Finally, as with many anthropological investigations, the power of this study was fairly low because of a quite modest sample size $(n=119)$. This limitation can potentially be overcome by pooling data across study populations via cross-cultural comparative work (e.g., Koster et al., 2020).

\section{CONCLUSION}

Ethnographic, archaeological, and paleoanthropological evidence indicate that long-distance social relationships in humans function to provide access to non-local resources and to manage the risk of resource shortfalls brought on by environmental variability (Pisor \& Surbeck, 2019). We have hypothesized, here and elsewhere (Pisor \& Jones, n.d.), that individuals will be more likely to manage risk using long-distance relationships when their exposure to environmental downsides is chronic, positively autocorrelated, and patterned (as opposed to rare). Focusing on how individuals might use their social networks to respond to climate change - namely, climate variability - we predicted that individuals in two communities of Bolivian horticulturalists would have more long-distance social relationships if they had experienced longer average intervals of drought or excess precipitation, shorter intervals of reprieve between intervals of drought or excess precipitation, and a higher frequency of unusually dry or wet months across their lifetimes. We found no support for any of these predictions, but instead found that individuals 
were using long-distance relationships for their first function: access to non-local resources (Pisor $\&$ Ross, n.d.). We should not point to these results from Bolivia to conclude that humans do not use long-distance relationships to manage climate risks, given an abundance of evidence to the contrary; instead, we are reminded that the importance of behavioral adaptations involving longdistance relationships depends on the relative costs and benefits of other available adaptations. As researchers continue to study adaptations for managing the downsides of climate change in an attempt to better support vulnerable communities, we must include the study of longdistance relationships, given their past and contemporary relevance to communities around the globe.

Acknowledgments. Thanks to the collaborating Mosetén and Intercultural communities for their friendship and, well, collaboration; Jacinta Álvarez and Amira Siquimen for their help with interview design and demographic data collection; Abigail Page and an anonymous reviewer for feedback on a previous version of this manuscript; and UC Davis Evolutionary Anthropology journal club for helpful discussion.

Author contributions. Anne Pisor: conceptualization (lead), data curation, formal analysis (lead), funding acquisition, investigation, methodology, project administration, software, supervision, validation (lead), visualization, writing - original draft. James Holland Jones: conceptualization (supporting), formal analysis (supporting), validation (supporting), writing - review and editing.

Data, metadata, and code are available at http://doi.org/10.5281/zenodo.4065638.

Funding. Data collection was funded by the Max Planck Institute for Evolutionary Anthropology Department of Human Behavior, Ecology, \& Culture.

\section{REFERENCES}

Agrawal, A. (2010). Local institutions and adaptation to climate change. In R. Mearns \& A. Norton (Eds.), Social Dimensions of Climate Change: Equity and Vulnerability in a Warming World (pp. 173-198). The World Bank. https://doi.org/10.4337/9781785365119.00009

Aktipis, C. A., Cronk, L., \& de Aguiar, R. (2011). Risk-pooling and herd survival: an agent-based model of a Maasai gift-giving system. Human Ecology, 39(2), 131-140.

https://doi.org/10.1007/s10745-010-9364-9

Ashton, M. C., \& Lee, K. (2007). Empirical, theoretical, and practical advantages of the HEXACO model of personality structure. Personality and Social Psychology Review, 11(2), 150-166. https://doi.org/10.1177/1088868306294907

Barlow, J., Gardner, T. A., Lees, A. C., Parry, L., \& Peres, C. A. (2012). How pristine are tropical forests? An ecological perspective on the pre-Columbian human footprint in Amazonia and implications for contemporary conservation. Biological Conservation, 151(1), 45-49. https://doi.org/10.1016/j.biocon.2011.10.013

Barth, F. (1969). Ethnic Groups and Boundaries: The Social Organization of Culture Difference. Waveland Press. 
Bermejo, M. (2004). Home-range use and intergroup encounters in western gorillas (Gorilla g. gorilla) at Lossi forest, North Congo. American Journal of Primatology, 64(2), 223-232. https://doi.org/10.1002/ajp.20073

Berry, J. W. (1997). Immigration, acculturation, and adaptation. Applied Psychology, 46(1), 568.

Bird, D. W., Bird, R. B., Codding, B. F., \& Zeanah, D. W. (2019). Variability in the organization and size of hunter-gatherer groups: Foragers do not live in small-scale societies. Journal of Human Evolution, 131, 96-108. https://doi.org/10.1016/j.jhevol.2019.03.005

Bollig, M. (2006). Risk management in a hazardous environment: A comparative study of two pastoral societies. Springer.

Bouzouggar, A., Barton, N., Vanhaeren, M., d’Errico, F., Collcutt, S., Higham, T., Hodge, E., Parfitt, S., Rhodes, E., Schwenninger, J.-L., Stringer, C., Turner, E., Ward, S., Moutmir, A., \& Stambouli, A. (2007). 82,000-year-old shell beads from North Africa and implications for the origins of modern human behavior. Proceedings of the National Academy of Sciences of the United States of America, 104(24), 9964-9969. https://doi.org/10.1073/pnas.0703877104

Braun, D. P., \& Plog, S. (1982). Evolution of "tribal" social networks: Theory and prehistoric North American evidence. American Antiquity, 47(3), 504-525. https://doi.org/10.1525/aa.1961.63.5.02a00100

Brewer, M. B., \& Campbell, D. T. (1976). Ethnocentrism and Intergroup Attitudes: East African Evidence. Sage.

Brooks, A. S., Yellen, J. E., Potts, R., Behrensmeyer, A. K., Deino, A. L., Leslie, D. E., Ambrose, S. H., Ferguson, J. R., D’Errico, F., Zipkin, A. M., Whittaker, S., Post, J., Veatch, E. G., Foecke, K., \& Clark, J. B. (2018). Long-distance stone transport and pigment use in the earliest Middle Stone Age. Science, 360(6384), 90-94. https://doi.org/10.1126/science.aao2646

Buchan, N. R., Grimalda, G., Wilson, R., Brewer, M., Fatas, E., \& Foddy, M. (2009). Globalization and human cooperation. PNAS, 106(11), 1-5.

Bürkner, P. C. (2017). brms: An R package for Bayesian multilevel models using Stan. Journal of Statistical Software, 80(1). https://doi.org/10.18637/jss.v080.i01

Cashdan, E. (1985). Coping with risk: Reciprocity among the Basarwa of Northern Botswana. Man, 20(3), 454-474.

Chapais, B. (2008). Primeval Kinship: How Pair-Bonding Gave Birth to Human Society. Harvard University Press.

Clement, C. R., Denevan, W. M., Heckenberger, M. J., Junqueira, A. B., Neves, E. G., Teixeira, W. G., \& Woods, W. I. (2015). The domestication of amazonia before european conquest. Proceedings of the Royal Society B: Biological Sciences, 282(1812). https://doi.org/10.1098/rspb.2015.0813

Colson, E. (1979). In good years and in bad: Food strategies of self-reliant societies. Journal of 
Anthropological Research, 35(1), 18-29. https://doi.org/10.2307/3629494

Dunham, A. E., Razafindratsima, O. H., Rakotonirina, P., \& Wright, P. C. (2018). Fruiting phenology is linked to rainfall variability in a tropical rain forest. Biotropica, 50(3), 396404. https://doi.org/10.1111/btp.12564

Fafchamps, M. (1992). Solidarity networks in preindustrial societies: rational peasants with a moral economy. Economic Development \& Cultural Change, 41(1), 147-174. https://doi.org/10.1086/452001

Fessler, D. M. T., Clark Barrett, H., Kanovsky, M., Stich, S., Holbrook, C., Henrich, J., Bolyanatz, A. H., Gervais, M. M., Gurven, M., Kushnick, G., Pisor, A. C., von Rueden, C., \& Laurence, S. (2015). Moral parochialism and contextual contingency across seven societies. Proceedings of the Royal Society B: Biological Sciences, 282(1813).

https://doi.org/10.1098/rspb.2015.0907

Field, C. B., Barros, V. R., Mach, K. J., \& Mastrandrea, M. D. (2014). Technical summary. In Climate Change 2014: Impacts,Adaptation, and Vulnerability. Part A: Global and Sectoral Aspects. Contribution of Working Group II to the Fifth Assessment Report of the Intergovernmental Panel on Climate Change (pp. 35-94). Cambridge University Press. https://www.ipcc.ch/site/assets/uploads/2018/02/WGIIAR5-TS_FINAL.pdf

Fitzhugh, B., Colby Phillips, S., \& Gjesfjeld, E. (2011). Modeling hunter-gatherer information networks: An archaeological case study from the Kuril Islands. In Information and its Role in Hunter-Gatherer Bands (pp. 85-115).

Foley, R., \& Gamble, C. (2009). The ecology of social transitions in human evolution. Philosophical Transactions of the Royal Society of London. Series B, Biological Sciences, 364(1533), 3267-3279. https://doi.org/10.1098/rstb.2009.0136

Forbes, H. (1989). Of grandfathers and grand theories: The hierarchised ordering of responses to hazard in a Greek rural community. In P. Halstead \& J. O'Shea (Eds.), Bad Year Economics: Cultural Responses to Risk and Uncertainty (p. 87). Cambridge University Press.

Freeman, J., Hard, R. J., \& Mauldin, R. P. (2017). A theory of regime change on the Texas Coastal Plain. Quaternary International, 446(March), 83-94. https://doi.org/10.1016/j.quaint.2016.12.029

Fruth, B., \& Hohmann, G. (2018). Food sharing across borders. Human Nature, 29(2), 91-103. https://doi.org/10.1007/s12110-018-9311-9

Gillespie, J. H. (1977). Natural selection for variances in offspring numbers: A new evolutionary principle. The American Naturalist, 111(981), 1010-1014.

Godoy, R., Tanner, S., Reyes-Garcia, V., Leonard, W. R., McDade, T. W., Vento, M., Broesch, J., Fitzpatrick, I. C., Giovanni, P., Huanca, T., Jha, N., \& TAPS Bolivian Study Team. (2008). The effect of rainfall during gestation and early childhood on adult height in a foraging and horticultural society of the Bolivian Amazon. American Journal of Human Biology, 20, 2334. https://doi.org/10.1002/ajhb.20679

Granovetter, M. S. (1973). The strength of weak ties. American Journal of Sociology, 78(6), 
1360-1380.

Halstead, P., \& O'Shea, J. (1982). A friend in need is a friend indeed: Social storage and the origins of social ranking. In C. Renfrew \& S. Shennan (Eds.), Ranking, Resource and Exchange (pp. 92-99). Cambridge University Press.

Halstead, P., \& O'Shea, J. (1989). Introduction: Cultural responses to risk and uncertainty. In P. Halstead \& J. O'Shea (Eds.), Bad Year Economics: Cultural Responses to Risk and Uncertainty (pp. 1-7). Cambridge University Press.

Harpending, H., \& Davis, H. (1977). Some implications for hunter-gatherer ecology derived from the spatial structure of resources. World Archaeology, 8(3), 275-286. https://doi.org/10.1080/00438243.1977.9979673

Headland, T. N., \& Reid, L. A. (1989). Hunter-gatherers and their neighbors from to the prehistory present. Current Anthropology, 30(1), 43-51.

Hijmans, R. (n.d.). DIVA-GIS. Retrieved May 1, 2020, from http://www.diva-gis.org/gdata

Hill, K. R., Wood, B. M., Baggio, J., Hurtado, A. M., \& Boyd, R. T. (2014). Hunter-gatherer interband interaction rates: Implications for cumulative culture. PLOS ONE, 9(7). https://doi.org/10.1371/journal.pone.0102806

Hruschka, D. J. (2010). Friendship: Development, Ecology, and Evolution of a Relationship. University of California Press.

Hruschka, D. J., Efferson, C., Jiang, T., Falletta-Cowden, A., Sigurdsson, S., McNamara, R., Sands, M., Munira, S., Slingerland, E., \& Henrich, J. (2014). Impartial institutions, pathogen stress and the expanding social network. Human Nature, 25, 567-579. https://doi.org/10.1007/s12110-014-9217-0

Jaeggi, A. V., Hooper, P. L., Beheim, B. A., Kaplan, H., \& Gurven, M. (2016). Reciprocal Exchange Patterned by Market Forces Helps Explain Cooperation in a Small-Scale Society. Current Biology, 26(16), 2180-2187. https://doi.org/10.1016/j.cub.2016.06.019

Jones, J. H., \& Pisor, A. C. (n.d.). Adaptation from afar: Spatial autocorrelation and the management of livelihood risk through exchange.

Kelly, R. L. (2007). The Foraging Spectrum: Diversity in Hunter-gatherer Lifeways (2nd ed.). Percheron Press.

Klein, H. S. (2011). A Concise History of Bolivia, Second Edition. Cambridge University Press. http://gen.lib.rus.ec/search.php?req=metcalf+india\&amp;open=0\&amp;view=simple\&am p;phrase=1\&amp;column=def

Koster, J., McElreath, R., Hill, K., Yu, D., Shepard, G., van Vliet, N., Gurven, M., Trumble, B., Bird, R. B., Bird, D., Codding, B., Coad, L., Pacheco-Cobos, L., Winterhalder, B., Lupo, K., Schmitt, D., Sillitoe, P., Franzen, M., Alvard, M., ... Ross, C. (2020). The life history of human foraging: Cross-cultural and individual variation. Science Advances, 6(26). https://doi.org/10.1126/sciadv.aax9070

Kruschke, J. (2014). Doing bayesian data analysis: A tutorial with R, jags, and Stan (2nd editio). 
Academic Press, Inc.

Lathrap, D. W. (1973). The antiquity and importance of long-distance trade relationships in the moist tropics of Pre-Columbian South America. World Archaeology, 5(2), 170-186.

Lucchesi, S., Cheng, L., Janmaat, K., Mundry, R., Pisor, A., \& Surbeck, M. (2020). Beyond the group: How food, mates and group size influence inter-group encounters in wild bonobos. Behavioral Ecology, arz214. https://doi.org/10.1093/beheco/arz214

McKee, T. B., Doesken, N. J., \& Kliest, J. (1993). The relationship of drought frequency and duration to time scales. Proceedings of the 8th Conference on Applied Climatology, 17(22), 179-183.

McLeman, R. (2018). Thresholds in climate migration. Population and Environment, 39(4), 319338. https://doi.org/10.1007/s11111-017-0290-2

Minc, L. D., \& Smith, K. P. (1989). The spirit of survival: cultural responses to resource variability in North Alaska. In P. Halsread \& J. O'Shea (Eds.), Bad Year Economics: Cultural Responses to Risk and Uncertainty (pp. 8-39). Cambridge University Press. https://doi.org/10.1017/CBO9780511521218.003

Miner, E. J., Gurven, M., Kaplan, H., \& Gaulin, S. J. C. (2014). Sex difference in travel is concentrated in adolescence and tracks reproductive interests. Proceedings of the Royal Society B: Biological Sciences, 281(1796), 20141476-20141476. https://doi.org/10.1098/rspb.2014.1476

Minnis, P. E. (1985). Social Adaptation to Food Stress: A Prehistoric Southwestern Example. University of Chicago Press.

Mintz, S. W., \& Wolf, E. R. (1950). An analysis of ritual co-parenthood (compadrazgo). Southwestern Journal of Anthropology, 6(4), 341-368.

Moya, C., \& Boyd, R. (2015). Different Selection Pressures Give Rise to Distinct Ethnic Phenomena. Human Nature, 26(1), 1-27. https://doi.org/10.1007/s12110-015-9224-9

Nannestad, P., Svendsen, G. L. H., \& Svendsen, G. T. (2008). Bridge over troubled water? Migration and social capital. Journal of Ethnic and Migration Studies, 34(4), 607-631. https://doi.org/10.1080/13691830801961621

Nettle, D. (2006). The evolution of personality variation in humans and other animals. The American Psychologist, 61(6), 622-631. https://doi.org/10.1037/0003-066X.61.6.622

Nettle, D. (2009). Personality: What Makes You the Way You Are. Oxford University Press.

Nordenskiöld, E. (1915). Exploraciones y aventuras en Sudamerica (G. Birk \& A. Garcia (eds.)). Apoyo para el Campesino-Indígena del Oriente de Bolivia.

O'Shea, J. (1981). Coping with scarcity: Exchange and social storage. In A. Sheridan \& G. Bailey (Eds.), Economic Archaeology: Towards an Integration of Ecological and Social Approaches (B.A.R. Int, pp. 167-181). B.A.R.

Orlowsky, B., \& Seneviratne, S. I. (2013). Elusive drought: Uncertainty in observed trends and 
short-and long-term CMIP5 projections. Hydrology and Earth System Sciences, 17(5), 1765-1781. https://doi.org/10.5194/hess-17-1765-2013

Palloni, A., Massey, D. S., Ceballos, M., Espinosa, K., \& Spittel, M. (2001). Social capital and international migration: A test using information on family networks. American Journal of Sociology, 106(5), 1262-1298.

Pan, L. (2009). Risk pooling through transfers in rural ethiopia. Economic Development and Cultural Change, 57(4), 809-835. https://doi.org/10.1086/598766

Pareja, L. Q. (1999). Procesos comunicacionales en la recreacion de la matriz cultural de la comunidad indigena Moseten de Covendo. Universidad Catolica Boliviana.

Pendergrass, A. G., Knutti, R., Lehner, F., Deser, C., \& Sanderson, B. M. (2017). Precipitation variability increases in a warmer climate. Scientific Reports, 7(1), 17966.

Pereira Morató, R. (2011). Perfil Migratorio de Bolivia.

Pisor, A. C., \& Gurven, M. (2015). Corruption and the other(s): Scope of superordinate identity matters for corruption permissibility. Plos One, 10(12), e0144542. https://doi.org/10.1371/journal.pone.0144542

Pisor, A. C., \& Gurven, M. (2018). When to diversify, and with whom? Choosing partners among out-group strangers in lowland Bolivia. Evolution and Human Behavior, 39(1), 30-39. https://doi.org/10.1016/j.evolhumbehav.2017.09.003

Pisor, A. C., \& Jones, J. H. (n.d.). The proper study of humankind is risk management.

Pisor, A. C., \& Ross, C. T. (n.d.). Parochialism is in the method.

Pisor, A. C., \& Surbeck, M. (2019). The evolution of intergroup tolerance in nonhuman primates and humans. Evolutionary Anthropology: Issues, News, and Reviews, 28(4), 210-223. https://doi.org/10.1002/evan.21793

Prein, A. F., Rasmussen, R. M., Ikeda, K., Liu, C., Clark, M. P., \& Holland, G. J. (2017). The future intensification of hourly precipitation extremes. Nature Climate Change, 7(1), 48-52.

Price, M. H., \& Jones, J. H. (2020). Fitness-maximizers employ pessimistic probability weighting for decisions under risk. Evolutionary Human Sciences, 2(e28). https://doi.org/10.1017/ehs.2020.28

Purzycki, B. G., Apicella, C., Atkinson, Q. D., Cohen, E., McNamara, R. A., Willard, A. K., Xygalatas, D., Norenzayan, A., \& Henrich, J. (2016). Moralistic gods, supernatural punishment and the expansion of human sociality. Nature, 530(7590), 327-330. https://doi.org/10.1038/nature16980

Purzycki, B. G., \& Lang, M. (2019). Identity fusion, outgroup relations, and sacrifice: A crosscultural test. 2Cognition, 186, 1-6. https://doi.org/10.1016/j.cognition.2019.01.015

R Core Team. (2020). R: A language and environment for statistical computing. R Foundation for Statistical Computing. http://www.r-project.org/

Ragno, E., AghaKouchak, A., Love, C. A., Cheng, L., Vahedifard, F., \& Lima, C. H. R. (2018). 
Quantifying changes in future intensity-duration-frequency curves using multimodel ensemble simulations. Water Resources Research, 54(3), 1751-1764.

https://doi.org/10.1002/2017wr021975

Reeve, M.-E. (1993). Regional Interaction in the Western Amazon: The Early Colonial Encounter and the Jesuit Years: 1538-1767. Ethnohistory, 41(1), 106-138.

Rodseth, L., Wrangham, R. W., Harrigan, A. M., \& Smuts, B. B. (1991). The human community as a primate society. Current Anthropology, 32(3), 221-254.

Seiler, N., Boesch, C., Mundry, R., Stephens, C., \& Robbins, M. M. (2017). Space partitioning in wild, non-territorial mountain gorillas: The impact of food and neighbours. Royal Society Open Science, 4(170720).

Singer, P. (1981). The Expanding Circle: Ethics and Sociobiology. Farrar, Straus \& Giroux.

Spielmann, K. A. (1986). Interdependence among egalitarian societies. Journal of Anthropological Archaeology, 5, 279-312.

Stan Development Team. (2020). RStan: the R interface to Stan. $R$ package version 2.19.3. http://mc-stan.org/

Standardardized Precipitation Index (SPI) for global land surface (1949-2012). (2013). Research Data Archive at the National Center for Atmospheric Research Computational and Information Systems Laboratory. https://doi.org/10.5065/D6086397

Svoboda, M., Hayes, M., \& Wood, D. (2012). Standardized Precipitation Index User Guide. World Meteorological Organization. https://public.wmo.int/en/resources/library/standardizedprecipitation-index-user-guide

Tan, J., Ariely, D., \& Hare, B. (2017). Bonobos respond prosocially toward members of other groups. Scientific Reports, 7(1), 1-11. https://doi.org/10.1038/s41598-017-15320-w

Thornton, T. F., \& Manasfi, N. (2011). Adaptation-Genuine and Spurious: Demystifying Adaptation Processes in Relation to Climate Change. Environment and Society, 1(1), 132155. https://doi.org/10.3167/ares.2010.010107

Van Buuren, S., \& Groothuis-Oudshoorn, K. (2011). Multivariate Imputation by Chained Equations. Journal Of Statistical Software, 45(3), 1-67. https://doi.org/10.1177/0962280206074463

Vashro, L., \& Cashdan, E. (2015). Spatial cognition, mobility, and reproductive success in northwestern Namibia. Evolution and Human Behavior, 36(2), 123-129. https://doi.org/10.1016/j.evolhumbehav.2014.09.009

Waddell, E. (1975). How the Enga cope with frost: Responses to climatic perturbations in the Central Highlands of New Guinea. Human Ecology, 3(4), 249-273.

Wiessner, P. (1977). Hxaro: a Regional System of Reciprocity for Reducing Risk among the !Kung San.

Wiessner, P. (1982). Risk, reciprocity and social influences on !Kung San economics. In Politics 
and History in Band Societies (pp. 61-84). Cambridge University Press.

Wilson, T. D. (1998). Weak ties, strong ties: Network principles in Mexican migration. Human Organization, 57(4), 394-403. https://www.jstor.org/stable/44127536

Winterhalder, B., Lu, F., \& Tucker, B. (1999). Risk-Sensitive Adaptive Tactics: Models and Evidence from Subsistence Studies in Biology and Anthropology. Journal of Archaeological Research, 7(4), 301-348.

Woolcock, M., \& Narayan, D. (2000). Social capital: Implications for development theory, and policy. The World Bank Research Observer, 15(2), 225-249.

World Bank Group. (2020). Country: Bolivia. Climate Change Knowledge Portal. https://climateknowledgeportal.worldbank.org/country/bolivia

Yamagishi, T. (2011). Trust. 37-59. https://doi.org/10.1007/978-4-431-53936-0

Young, E. S., Frankenhuis, W. E., \& Ellis, B. J. (2020). Theory and measurement of environmental unpredictability. Evolution and Human Behavior. https://doi.org/10.1016/j.evolhumbehav.2020.08.006 


\section{Supporting Information:}

\section{Do people manage climate risk through long-distance relationships?}

Anne C. Pisor ${ }^{1,2 *} \&$ James Holland Jones ${ }^{3}$

\footnotetext{
${ }^{1}$ Department of Anthropology, Washington State University, Pullman, WA 99164-4910

${ }^{2}$ Department of Human Behavior, Ecology, \& Culture, Max Planck Institute for Evolutionary Anthropology

${ }^{3}$ Department of Earth System Science, Stanford University

*Corresponding author: anne.pisor@wsu.edu
}

Data, metadata, and code available at http://doi.org/10.5281/zenodo.4065638.

\section{CONTENTS}

1. Collaborating communities

2. Precipitation data

2.1 Additional limitations of the precipitation data

3. Statistical models

3.1 Sequential models

3.2 Weakly informative priors

3.3 Equidistant thresholds and unequal variance by community

3.4 Outliers removed during the model fitting process

3.5 Procedures to reduce participant identifiability

3.6 What are odds ratios and credible intervals?

4. Vignette data

Tables S1a-d. Descriptive statistics

Figure S1. Model estimates for reciprocal long-distance relationships robustness check Figure S2. Model estimates for same-community relationships as alternative outcome Figure S3. Model estimates for non-consanguineal same-community relationships robustness check 


\section{COLLABORATING COMMUNITIES}

The two collaborating communities of horticulturalists are introduced in the main text (Section 2.1). Here, we confine our discussion to additional relevant details that supplement the main text.

The first community, a multicultural (intercultural) community, was founded in the early 1970s by families who had come to the area to work in the quinine or who moved there as part of a voluntary government relocation program. The plurality of community members is first- or second-generation emigrants from the Bolivian highlands. After first relying solely on river transit, pack mules, or travel by foot to reach the local market town, the community gained road access in 1975 (Llojlla Roca, 2011), facilitating direct sales of cash crops to middlemen, short-term migration, and further emigration of families interested in horticulture or logging. This Intercultural community is located one hour's drive away from the market town and seven hours away from La Paz, the de facto national capital and largest nearby city.

The second community was founded by families who identify as Mosetén, a local indigenous group. As the Mosetén community at a local mission grew larger in the latter part of the $20^{\text {th }}$ century, a shortage of land forced families to establish horticultural plots further and further away from the mission community; in the late 1990s, they founded a new community to bring social services (including a school and health care) closer to their homes. In 2000, a stone-paved road to the community was completed, facilitating crop sales, short-term migration, and emigration (Pisor \& Gurven, 2018). This Mosetén community is one and a half hours from the local town and seven and a half hours from La Paz.

The majority of households in both communities derive most of their income from owned or rented fields in which they plant crops. The most common cash crops in the Intercultural community are plantains and bananas, citrus, and chocolate, while the most common in the Mosetén community are plantains and bananas, coconut, yuca, and papaya. Households supplement their agricultural incomes with wage labor, usually in others' fields (43\% of households); running stores or selling prepared food or drinks (13\%); driving taxis (11\%); and salaries, usually earned for teaching school or collaborating with oil companies (10\%). While most households subsist partially on foods they grow - especially rice, plantains, and yuca - they also rely on store-purchased foods, including butchered meats, pasta, bread, and vegetables.

\section{PRECIPITATION DATA}

Precipitation accumulation data were downloaded from the NCAR Computational and Information Systems Laboratory (Standardardized Precipitation Index (SPI) for Global Land Surface (1949-2012), 2013). These data are discussed in the main text; here, we confine our discussion to additional relevant details that supplement the main text.

SPI data were available for a range of different windows, from three months to 48 months in length. Each of these window lengths is useful for different purposes; for example, three month windows provide more insight into how precipitation affects agriculture, while 48 month windows provide more insight into how precipitation affects reservoirs or water tables (Svoboda 
et al., 2012). Given our interest in the impact of climate variability on human livelihoods, we focus on three-month windows: for the two communities in Bolivia, even one month of high precipitation can cause the failure of crucial cash crops, including papaya, cacao, and yuca.

\subsection{Additional limitations of the precipitation data}

Daily precipitation accumulation tends to follow a gamma distribution (Martinez-Villalobos \& Neelin, 2019). However, common practice in meteorological science is to average daily precipitation accumulation by month or by longer periods, up to 48 months in length, and then normalize these gamma-distributed data into a standard normal distribution called the Standard Precipitation Index (SPI) (Orlowsky \& Seneviratne, 2013). This approximation is appropriate if the shape parameter is large enough, which it usually is for precipitation data. In particularly arid environments, data can be too zero-inflated to be approximated by a gamma distribution (Mishra \& Singh, 2010). However, only one department in our data set - Tarapacá, in Chile - has many zero values for precipitation, and only two participants are coded as having lived in Tarapacá. As such, the potential effects of an inappropriate conversion of gamma to standardized normal in the case of Tarapacá is unlikely to affect our results.

The NCAR dataset did not include data from before 1949. We attempted to remedy this problem with raw data of daily weather station precipitation data from the National Oceanic and Atmospheric Administration, however there are few data available for Bolivian stations before the 1980s. We are thus unable to account for participants' exposure to precipitation if they were born before 1949; this affects a total of three participants. The NCAR dataset also did not include data from after 2012, affecting all participants in the sample. When we scale by months of exposure for testing $\mathrm{H} 3$, we thus scale only by the years or months of the participant's life for which precipitation data were available.

There is within-department variation in rainfall that is masked when the SPI for a particular month is averaged at the department level. For example, the La Paz Department includes rainforest, cloud forest, and Andean plateaus, all with a very different precipitation profile. However, because AP asked only about department of residence, we do not have finer-grained data with which to assess participants' exposure to precipitation.

\section{STATISTICAL MODELS}

We pre-registered the analyses reported here on the Open Science Framework: https://osf.io/5pdn3/. Exploratory analyses that were not pre-registered are flagged as such in the main text. AP pre-registered data collection too (https://osf.io/utwuf), although the goals of data collection differed from the hypotheses tested in this paper. We discuss our statistical models at length in the main text; we confine our discussion here to additional relevant details that supplement the main text.

\subsection{Sequential models}

Under sequential models, a participant cannot reach the next "level" of long-distance relationships without having reached the previous level first: one cannot have three longdistance relationships without first having had two (Bürkner \& Vuorre, 2019). We use continuous 
parameterization with our sequential models because we are interested in whether experience of drought or excess precipitation predicts attaining one long-distance relationship instead of zero, or two instead of one - that is, continuing past each level to the next (Bürkner \& Vuorre, 2019).

\subsection{Weakly informative priors}

We utilize very weakly informative priors for the models analyzed in this paper. Non-informative priors - commonly, flat priors with high lower and upper bounds - are usually an inappropriate choice for estimating parameter values: given that the null hypothesis is that predictors should not have any relationship with the outcome variable, the sampling process should focus on values closer to zero. To estimate the predictors of interest and control variables, we use the normal distribution with a mean of zero and a standard deviation of 10 as a prior. To estimate the random effect for community - reported as a standard deviation, which must be positive by definition we use a half-Cauchy distribution with a location parameter of 0 and shape parameter of 2 . The half-Cauchy distribution has a fat tail, however. When fitting one model with the alternative Poisson fit (see Section 2.4.1), the model had difficulty searching the parameter space for the random effect for community, though plots of the posterior distribution suggested the value was close to zero; we used a more narrow-tailed distribution, an exponential distribution with a scale parameter of 1 , to aid in the model-fitting process accordingly. For discussion of these choices of priors, see McElreath (2020).

\subsection{Equidistant thresholds and unequal variance by community}

We begin the modeling process by using flexible spacing between thresholds for each level of long-distance relationships. We do this because it may be more difficult for a participant with zero long-distance connections to build one compared to how difficult it is for a participant with two long-distance connections to build a third, meaning that more drought exposure may be required to cross the zero-to-one threshold compared to the two-to-three threshold. However, because assuming equidistance between thresholds involves estimating fewer parameters and thus increasing model power, we assessed whether the assumption of equidistance is appropriate for these models.

We found the assumption of equidistant thresholds (as opposed to flexible thresholds) warranted for all sequential model fits. We compared model fits with flexible thresholds - that is, where the unique spacing between each pair of thresholds is estimated as part of the model fitting process - and models fits with equidistant thresholds - where the identical spacing between each pair of thresholds is estimated as part of the model fitting process - using leave-one-out cross-validation (Bürkner \& Vuorre, 2019). By leaving out a single observation, refitting, and attempting to predict the value of the outcome variable for the omitted observation, and iterating that process, we can compare the ability of the flexible threshold and equidistant threshold models to predict omitted observations. This comparison is done using the leave-one-out information criterion (LOOIC). LOOIC has advantages over other comparison techniques for Bayesian models, such as the Akaike Information Criterion (AIC), as it incorporates model priors and does not assume that the outcome variable is normally distributed; it is also less sensitive to the choice of model priors than is the widely applicable information criterion (WAIC), making it a robust choice for our sequential models with weakly informative priors (Vehtari et al., 2017). As is standard practice 
for AIC, WAIC, and LOOIC, we compared the LOOIC of models with flexible and equidistant thresholds, selecting the model with the lowest LOOIC value. Model comparison suggested that the equidistance assumption was appropriate for all five main models (that is, those depicted in Figure 1 and discussed in the main text).

In ordinal models, it is possible that there is unequal variance in the outcome by group, which can lead to inaccurate model estimates (Bürkner \& Vuorre, 2019). Though the inclusion of a random effect for community estimates the amount of variation in the observed outcome due to community, it does not account for unequal variance in the latent variable that generated the different levels of friendship. Though this is more commonly a concern for cumulative models than for sequential models (Bürkner \& Vuorre, 2019), we conducted exploratory analyses to examine whether unequal variance between communities was a concern. The communityspecific intercepts returned by these analyses had $\mathrm{Cls}$ that included an OR of 1 , suggesting no unequal variance between communities. Further, these models generated unrealistic model estimates with large credible intervals, indicating substantial uncertainty in the model fitting process. As such, we do not report these models in the main text or Supporting Information; however, the code for running them can be found in our GitHub repository.

\subsection{Outliers removed during the model fitting process}

Exploratory data analysis indicated that outliers in the predictor variables could influence model fit for P1-P3. During the process of assessing different model fits, our first step was to fit a model in which we explicitly estimated the effect of the predictor of interest (e.g., average length of drought intervals or excess precipitation intervals) on the latent outcome; the latent outcome is called "discrimination," or "disc" (Bürkner \& Vuorre, 2019). We then examined plots of the predicted values for the latent outcome, disc, to look for the potential influence of outliers; see our GitHub repository for the relevant code.

Outliers appeared to influence fit for the P1 drought model $(n=2)$, as evidenced by both the plot of predicted values and, in the model fit including these participants, reduced estimated sample sizes for some variables and increased uncertainty in parameter estimates compared to a model fit excluding these participants. The P1 drought model reported in the main text (Table 1 ) excludes these individuals. In our checks of the other four main models, we found no evidence that outliers influenced model fits. See our GitHub repository for reproducible code.

\subsection{Procedures to reduce participant identifiability}

We took two major precautions to reduce the identifiability of our participants. First, we converted all participant identification numbers (PIDs) to randomized identification numbers (RIDs) so that even the researchers cannot recognize these participants in publicly accessible data. Further, note that these RIDs are different across papers published using this data set; merging data sets from across publications by RID is not possible. Second, after completing the process of model fitting, we binned participant birth years into five-year bins (e.g., 1971 became 1970; 1999 became 1995) to further reduce participant identifiability. The binning of birth years did not alter model results for the predictors of interest; for discussion of how these bins did move the credible intervals for the control variables, however, see comments in our code, available in our GitHub repository. 


\subsection{What are odds ratios and credible intervals?}

All models discussed in this paper use a logit link function $\left(\log \frac{p}{1-p}\right)$ to translate the linear combination of predictors, which can have values that range from -/+ infinity, to the ranges appropriate for an ordinal (e.g., 0-3) or binary (i.e., 0, 1) outcome; that means that our models return parameter estimates on the logit scale (also known as log odds). In order to make parameter estimates interpretable, we exponentiate these estimates and report an odds ratio (OR; $\frac{p}{1-p}$ ) for each parameter. The OR indicates the increased or decreased odds of having one additional long-distance friend (ordinal models) or of having a same-community relationship (binomial models) given a participant's level for a particular variable. For example, if the OR for the average length of a drought interval was 0.5 , that would indicate that for every additional month of length of a participant's average drought interval, they would be 0.5 times less likely to have a long-distance friend. Given we are using a Bayesian approach, we report credible intervals (Cls) rather than confidence intervals. Cls indicate the probability that the true model estimate falls within that range. We use $90 \%$ Cls here, which indicate that there is a $90 \%$ probability that the true estimate falls between the lower bound and the upper bound of the interval. To translate from the log odds (logit) to odds scale, we likewise exponentiate the lower and upper bounds of the Cls; note that because exponentiating converts numbers from a scale of magnitude to a linear scale, $\mathrm{Cls}$ are no longer centered around the parameter estimates after exponentiation.

\section{VIGNETTE DATA}

AP collected vignette data in March-June 2017 as part of the interview described in Section 2.2. She posed the following vignette to participants:

Imagínate que hubiera derrumbes y inundaciones, como ha pasado en 2014, y los fregarían a todos los productos. ¿Quién lo llamarías para prestarte unos B500 - a quién puedes acudirte?

Imagine that there are landslides and floods like those from 2014, and they destroy all the crops. Who would you call to borrow 500 bolivianos - to whom could you turn?

For the individual identified by the participant, AP recorded where they lived and their relationship to the participant. She created a binary index indicating whether the individual named lived in the same community as the participant. A total of 118 participants responded to the question; 78 named a same-community member (66\%) and 40 (34\%) named someone outside the community. 
Tables S1a-d. Descriptive statistics

(a) Ordinal variables that include zero in their range

\begin{tabular}{crrrc}
\hline Variable & Zero & One & Two & Three \\
\hline Long-Distance $^{*}$ & 30 & 35 & 27 & 27 \\
Reciprocal Long-Distance* $^{*}$ & 58 & 40 & 21 & \\
Same-Community* $^{*}$ Non-Con. Kin Same- & 32 & 87 & & \\
Community* & 103 & 16 & & \\
Smartphone & 46 & 73 & & \\
Vehicle & 84 & 35 & & \\
\hline
\end{tabular}

*All refer to relationships (e.g., "long-distance relationships"). Non-con. is non-consanguineal.

(b) Ordinal variables that include one in their range

\begin{tabular}{crrrc}
\hline Variable & One & Two & Three & Four \\
\hline $\begin{array}{c}\text { Extraversion: Stranger* } \\
\begin{array}{c}\text { Extraversion: } \\
\text { Conversation** }\end{array}\end{array}$ & 60 & 16 & 42 & \\
\hline
\end{tabular}

*This scale was coded as: "Never" $=1$, "Sometimes" $=2$, "Always" $=3$.

$* *$ This scale was coded as: "Never" = 1, "Rarely" = 2, "Sometimes" = 3, "Always" = 4. For more information, see metadata available on GitHub.

(c) Nominal variables

\begin{tabular}{ccc}
\hline Variable & One & Two \\
\hline $\begin{array}{c}\text { Community } \\
\text { Sex** }\end{array}$ & 52 & 67 \\
\hline
\end{tabular}

*Community One is the Intercultural community, Community Two is the Mosetén community.

**Sex One is female, Sex Two is male. 


\section{(d) Continuous variables}

\begin{tabular}{ccc}
\hline Variable & Mean & SD \\
\hline Percent Dry Months & 10.23 & 1.31 \\
Percent Wet Months & 10.62 & 1.92 \\
Mean Len. Drought & 6.39 & 0.46 \\
Mean Len. Excess P. & 5.80 & 0.82 \\
Mean Len. No D. or E.P. & 6.75 & 0.93 \\
Birth Year & 1973.92 & 12.04 \\
Depts. \& Countries Visited & 1.33 & 1.36 \\
\hline
\end{tabular}

$* P .=$ precipitation. D. $=$ drought. E.P. $=$ excess precipitation

Figure S1. Parameter estimates and $90 \%$ credible intervals for a robustness check of the five main models, treating reciprocity-based long-distance relationships as the outcome.

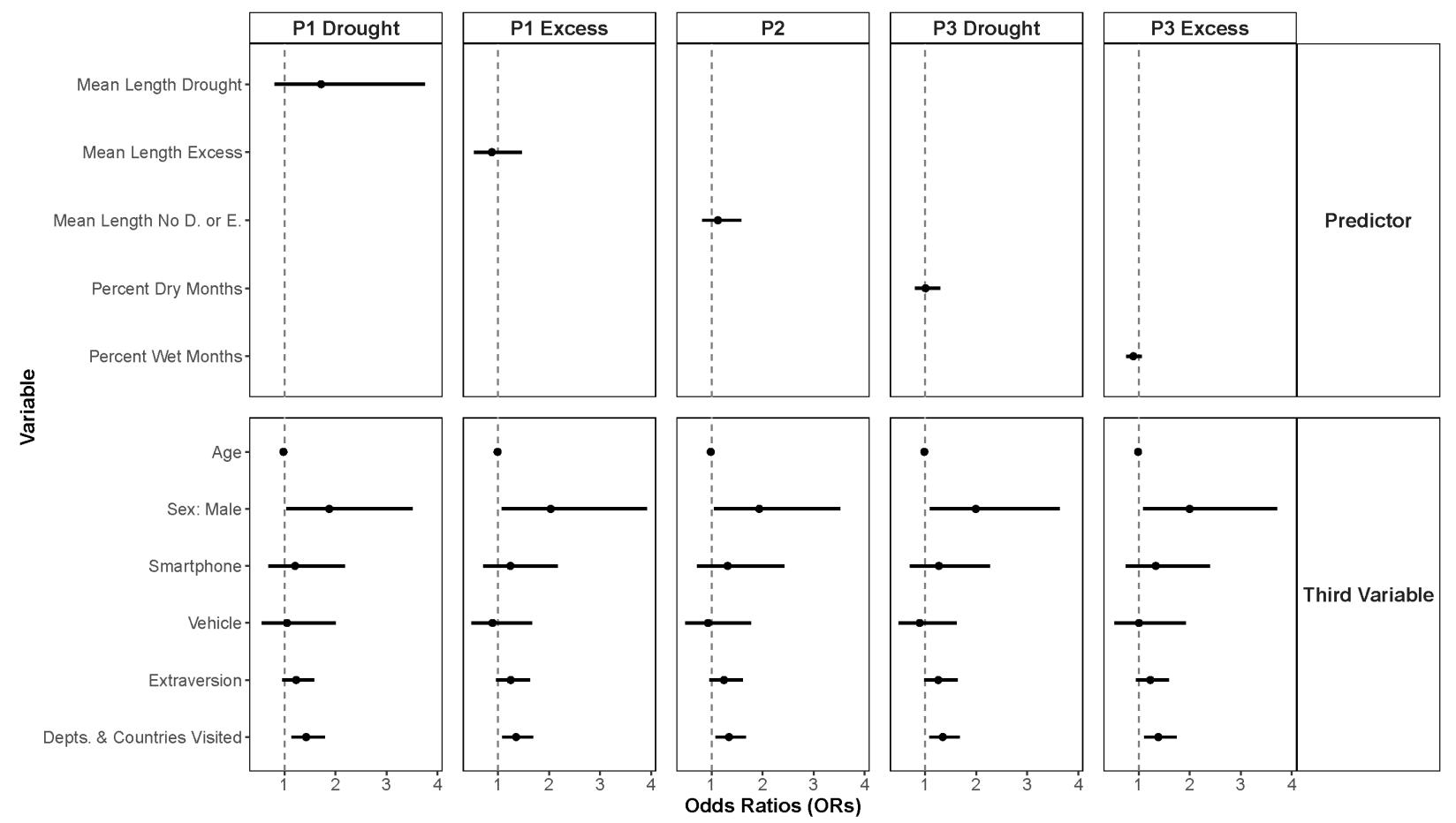


Figure S2. Parameter estimates and $90 \%$ credible intervals for an alternative outcome for the five main models, treating same-community relationships as the outcome.
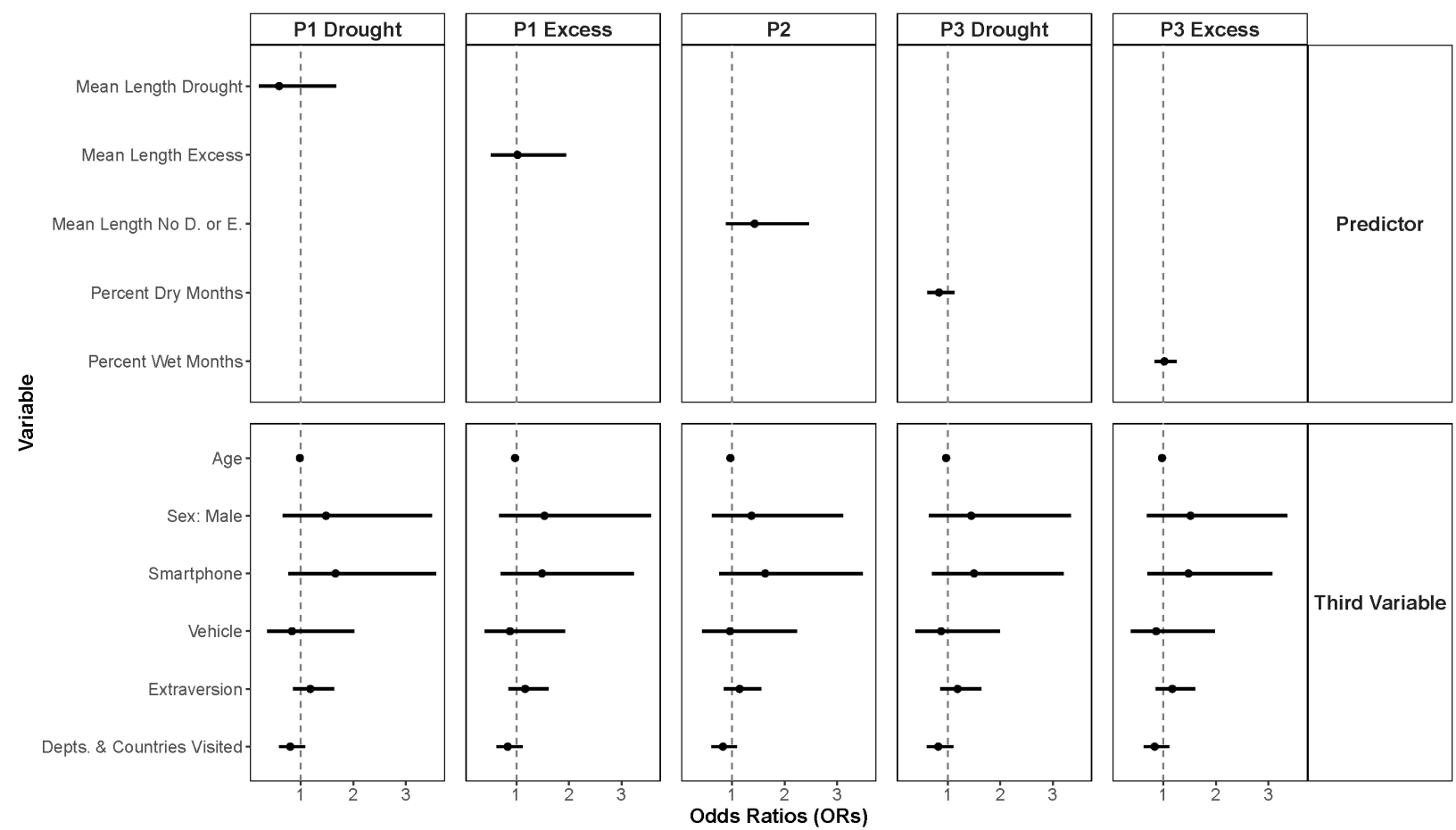

Figure S3. Parameter estimates and $90 \%$ credible intervals for a robustness check of the alternative outcome for the five main models, treating non-consanguineal same-community relationships as the outcome.
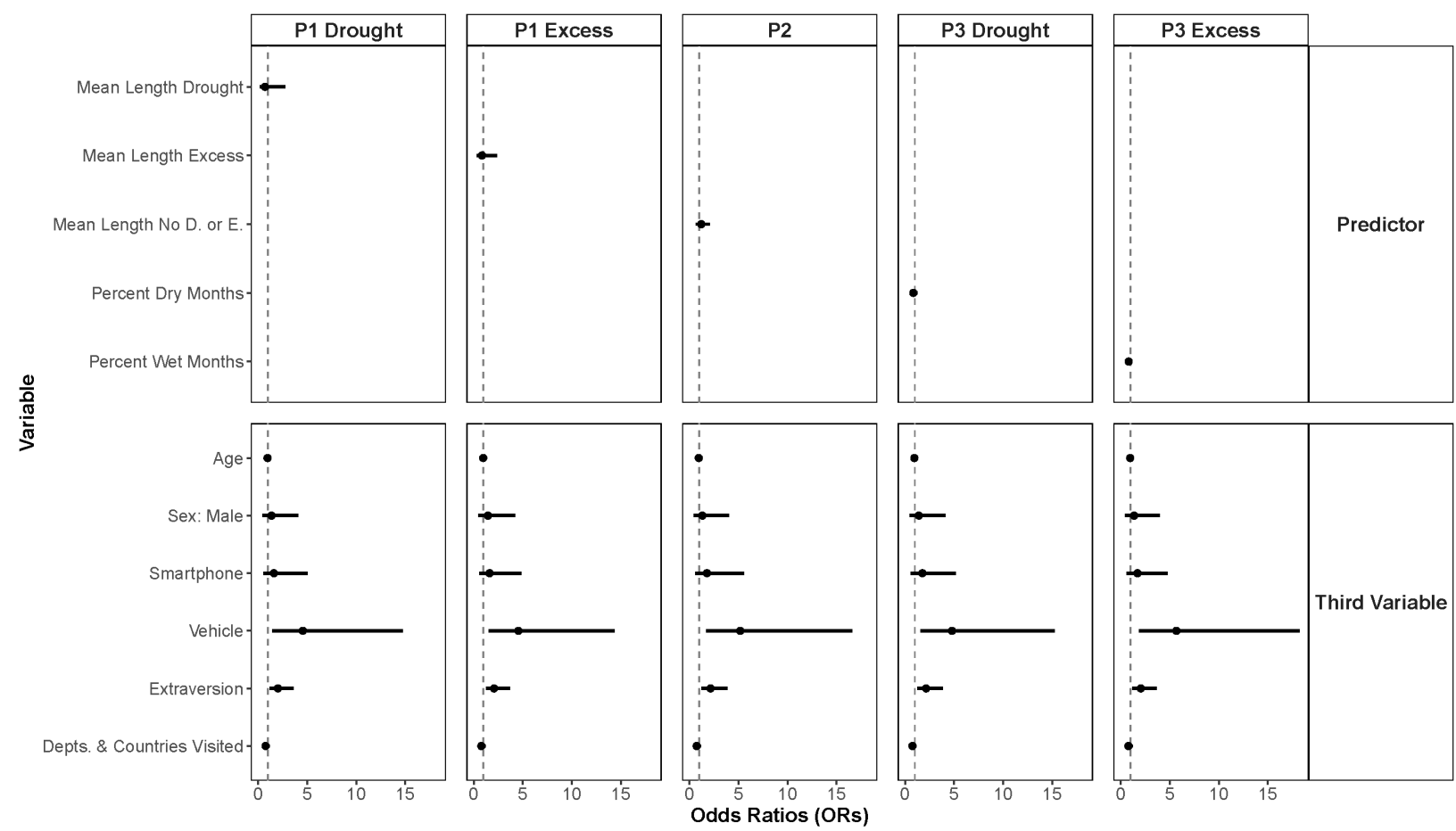


\section{REFERENCES}

Bürkner, P.-C., \& Vuorre, M. (2019). Ordinal regression models in psychology: A tutorial. Advances in Methods and Practices in Psychological Science, 2(1), 77-101. https://doi.org/10.1177/2515245918823199

Llojlla Roca, J. M. (2011). Historial de Tucupí.

Martinez-Villalobos, C., \& Neelin, J. D. (2019). Why do precipitation intensities tend to follow gamma distributions? Journal of the Atmospheric Sciences, 76(11), 3611-3631. https://doi.org/10.1175/JAS-D-18-0343.1

McElreath, R. (2020). Statistical Rethinking: A Bayesian Course with Examples in $R$ and STAN. Chapman and Hall/CRC.

Mishra, A. K., \& Singh, V. P. (2010). A review of drought concepts. Journal of Hydrology, 391(12), 202-216. https://doi.org/10.1016/j.jhydrol.2010.07.012

Orlowsky, B., \& Seneviratne, S. I. (2013). Elusive drought: Uncertainty in observed trends and short-and long-term CMIP5 projections. Hydrology and Earth System Sciences, 17(5), 1765-1781. https://doi.org/10.5194/hess-17-1765-2013

Pisor, A. C., \& Gurven, M. (2018). When to diversify, and with whom? Choosing partners among out-group strangers in lowland Bolivia. Evolution and Human Behavior, 39(1), 30-39. https://doi.org/10.1016/j.evolhumbehav.2017.09.003

Standardardized Precipitation Index (SPI) for global land surface (1949-2012). (2013). Research Data Archive at the National Center for Atmospheric Research Computational and Information Systems Laboratory. https://doi.org/10.5065/D6086397

Svoboda, M., Hayes, M., \& Wood, D. (2012). Standardized Precipitation Index User Guide. World Meteorological Organization. https://public.wmo.int/en/resources/library/standardizedprecipitation-index-user-guide

Vehtari, A., Gelman, A., \& Gabry, J. (2017). Practical Bayesian model evaluation using leave-oneout cross-validation and WAIC. Statistics and Computing, 27, 1413-1432.

https://doi.org/10.1007/s11222-016-9696-4 